NBER WORKING PAPER SERIES

\title{
TRANSITION POLICY: A CONCEPTUAL FRAMEWORK
}

\author{
Louis Kaplow \\ Working Paper 9596 \\ http://www.nber.org/papers/w9596 \\ NATIONAL BUREAU OF ECONOMIC RESEARCH \\ 1050 Massachusetts Avenue \\ Cambridge, MA 02138 \\ April 2003
}

I am grateful to Steven Shavell and to participants in a workshop at Harvard Law School and a conference at the University of San Diego for comments, Alexander Blenkinsopp, Aaron Houck, Zachary Price, and Jason Schall for research assistance, and the John M. Olin Center for Law, Economics, and Business at Harvard Law School for financial support. This article draws heavily on my prior work on the subject. Most comprehensive are Kaplow (1986) and Kaplow (1987), the latter being more formal and in certain respects broader in coverage (it previously appeared as a working paper in 1986, an earlier version of which is cited in the former article). Formal analyses also appear in Kaplow (1991a), which emphasizes market and natural risks; Kaplow (1992a), which focuses on government risk; and Kaplow (1993), which examines electric utility deregulation. Kaplow (1995a) expands on my previous analysis of the transition to a consumption tax. Kaplow (2000) is a brief survey that includes some of the subsequent literature in the field and addresses additional issues. The views expressed herein are those of the authors and not necessarily those of the National Bureau of Economic Research.

C2003 by Louis Kaplow. All rights reserved. Short sections of text not to exceed two paragraphs, may be quoted without explicit permission provided that full credit including Cnotice, is given to the source. 
Transition Policy: A Conceptual Framework

Louis Kaplow

NBER Working Paper No. 9596

April 2003

JEL No. H20, K11, K34, K40

\begin{abstract}
Legal change, whether through legislation, regulation, or court decision, is a common phenomenon, and virtually all reform creates both gains and losses for those who under the prior regime took actions that would have lasting effects. This article offers a conceptual framework for assessing the desirability of different transition policies, ranging from compensation of losses and taxation of gains, grandfathering of pre-enactment investments, and delayed or partial implementation to complete and immediate implementation or even retroactive application. Emphasis is placed on how transitions and various mitigation strategies affect the incentives of and risk borne by private actors as well as on the behavior of government and how it may be affected by transition policy.
\end{abstract}

\author{
Louis Kaplow \\ Harvard Law School \\ Hauser 322 \\ Cambridge, MA 02138 \\ and NBER \\ rroberts@law.harvard.edu
}




\section{Table of Contents}

I. Introduction

II. Scope of Question

A. Not Merely Nominally Retroactive Government Action

B. Range of Government Policy

C. Symmetry of Gains and Losses

III. Criteria for Assessment of Transition Policy

A. Welfare

B. Other Criteria

1. Reliance and expectations

2. Government as cause of harm

3. Fair distribution of benefits and burdens of government

4. Horizontal equity

IV. Assumptions and Distinctions

A. Assumptions Concerning Government Behavior

1. Transition policy

2. Underlying substantive policy

B. Distinctions Among Types of Reforms and Effects

1. Incidental versus intentional redistribution

2. Accounting changes versus intended incentive effects

3. Rules that regulate behavior versus default rules

V. Private Actors: Incentives and Risk

A. Basic Analysis

1. Analogy between government-created risks and risks due to market or natural forces

2. Illustration of inefficiency of government relief using natural disaster analogy

a. Incentive effects

b. Risk, incentives, and market versus government mitigation of risk

3. Application of analysis to transition mitigation

4. Mitigation of gains

5. The possible need for retroactive application

6. Comment on incentive effects, with special reference to tax reform

B. Additional Market Imperfections

1. Adverse selection

2. Administrative costs

3. Imperfect information by private actors

C. Different Forms of Transition Mitigation

1. Similarities

2. Differences

3. Variation: grandfathering implicit in program design

4. Variation: relief limited to uninsured losses 
VI. Government Behavior

A. Optimality of Government Behavior: Overview

1. Analysis of government behavior

2. Applicability of analysis of private actors when government policy is not optimal

B. Effects of Transition Policy on Government Behavior

1. Bilateral torts analogy

2. Fiscal illusion

3. Tyranny of the majority; abuse of power

4. Expropriation; capital levies

5. Political feasibility

6. Rent seeking

7. Binding future regimes

VII. Applications
A. Regulation of Newly Discovered Externalities
B. Takings
C. Electric Utility Deregulation
D. Transition from an Income Tax to a Consumption Tax
E. Government Contracting

VIII. Conclusion 


\section{Introduction}

The costs and benefits of many actions depend on future events, including the legal regime that will subsequently be in force. Accordingly, the prospect of legal transitions changes in governing rules - is relevant to most significant decisions that individuals and entities make.

When new government policies are implemented, they may be fully applied from that point forward to preexisting investments, retroactively extended to the past, or made applicable only to subsequent activity. And a variety of transition provisions can be implemented, including partial or full compensation of losses and taxation of gains, grandfathering, phase-ins, and so forth. Hence, with regard to the myriad government actions involving changes in legislation, regulation, the common law, government spending priorities, and other practices, there is always the question of what transition scheme should be employed.

This article offers a conceptual framework for analyzing transition policy. Rather than advocating particular transition rules in general or in specific contexts, it seeks to emphasize certain factors that need to be considered in most settings and, in many instances, to suggest how some of the analysis should be undertaken. ${ }^{1}$

Especially important but often slighted is the need to be explicit and consistent (and, ultimately, realistic) about one's assumptions, notably, assumptions concerning government behavior. This concerns both assumptions about how substantive policy decisions are made by government actors - legislatures, agencies, and courts - and also assumptions about transition policy itself, such as whether it is known by private parties in advance and will be followed consistently in the future. Sometimes it is helpful to make various stipulations about government behavior and determine optimal transition policy accordingly; this has been the approach in much of the literature, although not all authors make the same assumptions, the assumptions are not always explicit, and they may not be maintained consistently in subsequent analysis. In addition, it is important to analyze directly the question of how government is in fact likely to behave under various circumstances.

The investigation here will proceed as follows. Section II elaborates on the scope of the transition question, explaining a number of respects in which the problem is more pervasive than may seem apparent and emphasizing the often-overlooked symmetry of transition losses and transition gains. Section III comments briefly on the criteria that should be used in assessing transition policy. Section IV, echoing the foregoing remarks, emphasizes certain assumptions and distinctions that are important to keep in mind. Section V focuses on private actors, in particular, on how the prospect of transitions - and various forms of transition mitigation - affect incentives and risk-bearing. Section VI examines government behavior, regarding both

${ }^{1}$ This was also the purpose of my prior work on the subject, although various statements in Kaplow (1986) - often viewed without regard to surrounding qualifications that were meant to be taken seriously, but sometimes due to excessive exuberance or carelessness on my part - have occasionally been interpreted otherwise. 
transition policy and underlying substantive policy, including possible effects of the former on the latter. Section VII considers some applications, solely for purposes of illustrating how the analysis can be made more concrete. Section VIII offers concluding remarks.

It should be emphasized that the present discussion will often be rather compressed, referring the reader to prior work for clarification or leaving questions open for subsequent investigation. The reason is that this article aims to focus on the framework itself rather than on the analysis and resolution of transition issues in particular fields, such as taxation and takings, as in most of the pertinent literature. In addition, the analysis here is limited in a number of respects, largely ignoring problems of implementation, legal and other institutional constraints regarding transition policy, and various other matters.

\section{Scope of Question}

It is useful to define the transition question as arising whenever actors make decisions whose effects may be influenced by government policies that are not known with certainty at the time the decisions are made. To elaborate, consider three respects in which this definition is broad. $^{2}$

\section{A. Not Merely Nominally Retroactive Government Action}

Although most legal theorists had traditionally expressed concern only about explicitly (nominally) retroactive law - that is, new law that changed the legal status of prior actions ${ }^{3}-$ it has for some time been apparent that the subject is much broader. Graetz (1977, pp. 49-50, 5758) drove this point home in his analysis of tax reform. ${ }^{4}$ Consider, for example, an investment that pays off evenly over a thirty-year period. If a tax rule changes after the first year and is nominally prospective - applicable only to subsequent years - it is still the case that the remaining twenty-nine years of investment return will be affected; that the first year's return is exempt from the reform because the reform is not nominally retroactive is a modest detail from the investor's perspective.

Generalizing from this example, a transition issue will be said to arise whenever an act has future consequences and the legal regime applicable to those future consequences is not known with certainty at the outset. ${ }^{5}$ Because the legal world is in fact uncertain, and in some

${ }^{2}$ I first articulated and more fully elaborated the view that transition issues should be viewed as a general problem arising from uncertainty concerning future government action in Kaplow (1986, section 1; 1987, section 1.1).

${ }^{3}$ See, for example, the representative citations in Kaplow (1986, p. 515 \& n.3).

${ }^{4}$ For earlier discussions of the breadth of the problem, see, for example, Hale (1927) and Samuels (1974).

${ }^{5}$ It should be noted that change per se is irrelevant. Consider the case in which existing law provides for different treatment in future years but this treatment is known ex ante with certainty. Then there is no transition gain or loss in the sense meant here (even though the pattern of change may itself result from a prior transition, such as a phased-in reform). One can 
realms change is quite frequent, and moreover many actions have important future effects, the present consideration suggests that the transition phenomenon is quite far-reaching.

Explicit retroactivity should also be considered. It is possible - and, as will be explored, may sometimes be optimal - for new legal rules to apply to conduct entirely in the past. Hence, both acts whose effects are entirely instantaneous and those whose effects have fully transpired might be subject to subsequent reform. For example, actors may later be made to make payments on account of their prior disposal of materials now deemed to be hazardous.

\section{B. Range of Government Policy}

Transition issues are most commonly discussed by legal academics in the field of taxation and, to a lesser degree, tort liability. Explicit retroactivity is also considered by criminal law scholars. Although often classified as a separate problem, the subject is also addressed with regard to government takings. Additional areas include all types of regulation and deregulation, tariff and other trade policy, and government spending (whether through government contracting or otherwise). Indeed, it is difficult to think of government activity that does not present transition issues.

To illustrate the breadth of the subject, consider a particular investment decision: the choice of whether to go to medical school to develop one's human capital. The return to this investment may depend, among other things, on future tax policies, state regulation of the medical profession, federal legislation on health insurance, Medicare spending and reimbursement policies, expenditures on biomedical research, regulation of the pharmaceutical industry (including patent policy), rules on immigration of individuals with medical training, and legislative as well as court activity regarding medical malpractice liability. Even ignoring rules directly related to whether and how a medical school graduate may practice medicine, a vast array of government policies will influence the outcome of a decision to become a doctor.

Obviously, prevailing practice concerning transition mitigation varies widely: Takings are to be fully compensated, new tax rules are often nominally prospective, common law rules (such as in the area of tort liability) are generally deemed to be found rather than newly created and hence are generally applicable to past behavior, and parties affected by changes in government spending priorities are generally left bearing their gains or losses, unless some group successfully lobbies for different treatment.

This variance in policy with regard to similar phenomena itself suggests the need for investigation. In arguing that similar transition issues arise in virtually all areas of government policy, it is not being suggested that the optimal transition policy is the same in each instance although it is probably worth entertaining a weak presumption that transition policies should be

also consider a different sort of case, one with no actual change but with transition effects: Whenever there is a change in the probability of future reform, the value of an investment may rise or fall (including, for example, in the case in which a reform that previously had a nontrivial probability of enactment is no longer under consideration). 
the same in the absence of identifying good reasons that justify differences. Rather, the claim is that for analytical purposes it is useful to recognize that these seemingly different contexts raise many common questions and that some of the answers - notably those concerning how private actors are affected in terms of incentives and risk - may be the same. Furthermore, because most writing on transition policy is confined to particular fields, such as tax reform or takings, there are significant potential gains from cross-fertilization if the commonality of issues is better recognized.

\section{Symmetry of Gains and Losses}

As I have emphasized in all my prior writing on the subject, it is important to understand that transition gains are as ubiquitous as transition losses and to a substantial extent call for symmetric analysis. ${ }^{6}$ Regarding the effects themselves, just as a tax increase (through changing rates, exemptions, and other rules) may disadvantage one investment, a tax decrease may advantage another; regulations may impose both benefits and costs, and in either case, deregulation may have opposite effects; also, laws that help or hurt one firm may have opposite effects on competitors.

Furthermore, there is a strong prima facie case for analyzing these symmetric phenomena in a similar manner. In formal economic analysis, the equations would often be identical, and certain variables can simply take on positive or negative values. Regarding incentives, both gains and losses tend to have analogous effects. For risk, what matters is the distribution of possible returns and their corresponding probabilities; which outcome is designated the status quo is unimportant for most purposes, and although gains and losses of a given magnitude can have a different impact, the analysis is nevertheless similar. Government agents that ignore losses because they do not personally bear them may similarly ignore gains, and if concentrated losses are more likely to generate organized lobbying, so are concentrated gains.

It is not insisted that gains and losses may never require different analysis or different transition policies. But there does seem to be a strong basis for considering gains and losses together, and it seems that the correct treatment would often be similar. ${ }^{7}$

${ }^{6}$ When I first emphasized the need to consider gains and analyze them symmetrically Kaplow (1986, subsection II.C.2; 1987, subsection 2.3.2); see also Kaplow (1991a, p. 173; 1992a, pp. 533-34) - most analyses in various areas considered only losses. Fortunately, it is now more common - though still hardly widespread - to examine gains as well, although authors do not always consistently apply whatever framework is used to analyze losses. See, for example, Bell and Parchomovsky (2001b).

${ }^{7}$ In Kaplow (1986, p. 556), I suggested (with qualifications, see n.134) that revenue effects may provide an efficiency basis for distinguishing gains and losses. However, in Kaplow (1987, section 2.3.2), I offered a more complete and qualified view, one reinforced by subsequent, largely unrelated work. See Kaplow (1996) and also the qualifications to that analysis in Ng (2000) and Slemrod and Yitzhaki (2001). Nevertheless, asymmetric revenue effects may sometimes be important for political reasons. 
Despite this symmetry, I will often focus on the case of transition losses and transition relief for simplicity and due to readers' expectations. Nevertheless, with rare exception all analysis herein should be interpreted as applicable to gains as well as to losses and relief should usually be interpreted to include mitigation of gains. (Thus references to compensation should usually be understood to encompass taxation of gains; grandfathering and other transition mechanisms tend automatically to provide symmetric treatment of gains and losses.)

\section{Criteria for Assessment of Transition Policy}

\section{A. Welfare}

The analysis in following sections will take the objective to be the advancement of individuals' well-being. This objective is controversial in the legal academy, including with regard to transition policy, but it will not be explicitly defended here due to space constraints and the existence of other work on the subject. ${ }^{8}$

In the present context, a welfarist view will generally imply that attention should be focused on the efficiency of behavioral effects and risk-bearing costs. ${ }^{9}$ It is important to examine these effects explicitly rather than relying on vague criteria such as encouraging investment, protecting expectations, and so forth. Some of these other, commonly invoked criteria may well serve as proxies for the advancement of welfare, but analysis based on such intermediate principles can be misleading. ${ }^{10}$ This is especially so with a subject like that involving transitions, where the analysis is often subtle and the matter itself involves a sort of meta-problem.

${ }^{8}$ For a defense of welfarism, with extensive citation to and discussion of competing views, see Kaplow and Shavell (2002).

${ }^{9}$ In principle, the distribution of income is also relevant. In the transition setting, however, most issues that might loosely be described as distributive really involve questions of risk-bearing, given the ex ante nature of the analysis. As subsection IV.B.1 indicates, these effects will be distinguished from intentional redistribution, such as when tax rates are changed to adjust the tax burdens of different income classes.

It is also possible that individuals have tastes for government relief, in the sense that they feel bad if the government, say, takes someone's home and offers no compensation. (In a world with no compensation requirement, and in which private insurance markets were accordingly more developed, it is not clear how strong such feelings would be.) In such instances, this factor would be relevant under welfarism, to an extent determined by the strength, assessed empirically, of individuals' actual tastes and how they were affected by various government transition policies.

${ }^{10}$ Of course, these other notions might be invoked as independent evaluative principles, taken to be important in themselves, as explored in section B. Alternatively, they might be used as tests or rules of thumb, for example, by courts (think of takings doctrine), who either find them useful or feel bound to apply them due to the prevailing understanding of legal constraints. These latter uses could, in theory, be justified; whether existing practice in this regard is actually warranted is not considered here. 


\section{B. Other Criteria}

This section notes a number of other criteria often invoked in the transition context and briefly indicates why they are deficient. More complete analysis appears elsewhere. ${ }^{11}$

1. Reliance and expectations. - Although commonplace in most transition settings, it is increasingly recognized that arguments based on actors' reliance on and expectations concerning existing law are circular and otherwise deficient. As a matter of fact, law often changes, in some areas (notably tax) at a breathtaking rate, and actors are aware of this. ${ }^{12}$ Moreover, in principle, the very existence of legislatures, regulators, and courts with lawmaking authority belies the notion that there is some sort of legal entitlement that law will not change. ${ }^{13}$ Furthermore, arguments both for and against transition relief tend to be circular: If no relief is the norm, one cannot reasonably expect relief to be forthcoming, but if relief is the norm, it can indeed be expected; hence, in determining what, if any, relief should ordinarily be provided, expectations cannot provide the answer. Answering this normative question requires offering reasons, which actors' predictions about the future under any particular existing regime do not provide.

2. Government as cause of harm. - In some settings, such as takings, it may be suggested that the government should compensate losers because it has caused them harm, following principles analogous to those of corrective justice in the tort context. But the analogy is just that: The government is a qualitatively different type of actor from a private party, so it is not obvious

${ }^{11}$ See especially Kaplow (1986, sections II.A.1, II.D.1, and III.B). (Among other points, it is suggested, see id. p. 579-80 n.206, that many of these other criteria might be proxies for welfarist objectives that are mistakenly taken to be first principles as a consequence of overgeneralization.) Interestingly, most of these theories are invoked to justify relief for transition losses, while little is said of the implication for mitigation of transition gains, such as through taxation.

To the extent that nonwelfarist criteria are to be defended as independent evaluative principles in the transition setting, they would be subject to the analysis in Kaplow and Shavell (2002). In particular, proponents ought to be able to state the relevant principles with some clarity, offer explicit rationales - including reasons that the principles should be pursued at the expense of (possibly everyone's) well-being - and address alternative, welfarist explanations for the intuitions underlying proposed nonwelfarist principles.

${ }^{12}$ Fisch (1997) argues that individuals should be protected when law previously in "equilibrium" (that is, long settled law that appears to have a very low probability of changing) is reformed. Of course, there would be practical problems in identifying such laws; furthermore, the fact that legal change is never instantaneous, so that the very low initial probability would first rise - making her principle then seem inapplicable - before reform actually occurs. More relevant for present purposes, however, the normative basis for protecting such reliance is unclear, especially if in fact the prevailing norm were, as discussed in the text to follow, that no protection was available in such cases.

${ }^{13}$ For further discussion of the point, see section VII.E, discussing the aptness and implications of the analogy between changes in the law and breach of contract. 
that the analogy holds, as will be explored further in section VI. ${ }^{14}$ Furthermore, theories of corrective justice are arguably inapplicable (because they require the injurer to have acted wrongfully), and in any event they do not really provide a normative basis for requiring compensation (much less for determining when compensation is warranted). ${ }^{15}$

3. Fair distribution of benefits and burdens of government. - Another suggestion is that transition relief is justified in order that certain individuals do not shoulder an unfair share of the burdens of government. Such theories are often question-begging, in that they may have difficulty specifying the baseline for determining what counts as an unfair burden. It is also the case that, from an ex ante perspective, such matters can be more fully, precisely, and appropriately analyzed in a welfarist framework as problems concerning the imposition of risk, as will be seen in section V.A. ${ }^{16}$

4. Horizontal equity. - The concept of horizontal equity is most commonly invoked in the tax setting, often by economists. ${ }^{17}$ The principle, which requires equal treatment of equals, may have similar implications to the foregoing concern with fair distribution (which similarly objects on inequality in the bearing of burdens of government action). In addition, transitions can have arbitrary effects that seem to violate horizontal equity, because similarly situated individuals may have taken what were materially equivalent actions ex ante that, due to subsequent changes in government policy, ultimately have different effects (for example, investments in activities that prior to a reform had identical after-tax returns but no longer do afterwards). Once again, however, the problem is better understood in welfarist terms when analyzing risk-bearing costs. As an independent principle, horizontal equity is deeply problematic. ${ }^{18}$

\section{Assumptions and Distinctions}

\section{A. Assumptions Concerning Government Behavior}

As emphasized in the introduction, it is quite important in attempting to determine optimal transition policy to be clear and consistent about one's assumptions, particularly those

${ }^{14}$ See also Fischel and Sykes (1999). The strength of the analogy depends on whether the analysis of government behavior, see section VI, may differ from that of private actors; obviously, it can, even if in some settings it turns out that it does not. Thus, the analogy can be seen as a proxy, encouraging the analyst to consider the question of government behavior, but not as much of a guide to analysis and certainly not as an independent evaluative principle.

${ }^{15}$ For a review and critique of the corrective justice literature, see Kaplow and Shavell (2002, ch. III).

${ }^{16}$ See also Kaplow (1989), developing the idea in the context of arguments phrased in terms of horizontal equity.

${ }^{17}$ See, for example, Auerbach and Hassett (2001), Feldstein (1976), King (1983), and Musgrave (1990).

${ }^{18}$ See Kaplow (1989, 1995b, 2001); see also Westen (1982). For a defense, see Musgrave (1990). 
concerning government behavior. ${ }^{19}$ For much of the analysis here, especially in section V, certain assumptions will be made in this regard. These assumptions, it should be noted, are not offered because of a belief about their realism in any particular transition context; rather, they are made merely to focus the inquiry into a problem that is reasonably complex even when a number of factors are set aside. Indeed, most of the discussion in section VI will be concerned with how relaxing the second assumption may affect the analysis.

1. Transition policy. - In considering what transition policy would be optimal, it is useful to assume that a transition policy under consideration is both known by all concerned ex ante, at the time various investment decisions are made, and will be implemented ex post. Although subsequent analysis will suggest that often it may be desirable for individuals all to act ex ante as if they expect one policy but then to implement a different policy - just as it may be optimal to have a firm policy of no disaster relief to induce individuals to take appropriate precautions but then to bail out those whose uncontrollable imprudence leads them to folly such an approach is not sustainable over time. A government that consistently delivers $X$ despite promising $Y$ will ultimately be expected to deliver $X$; the promises about $Y$ will eventually be ignored. Thus, if the question is what transition policy would be best in the long run, it is insufficient, indeed, misleading, to ask what transition policy has the best effects taking behavior as given. Instead, one should determine the ex ante effects of a fully anticipated transition policy.

This assumption, although most appropriate for normative analysis, does raise further questions. Notably, how should one implement - that is, make the transition to - the optimal transition policy? What if a major reform is presently under consideration but there is no clear understanding of what transition policy would accompany it if enacted? And how does a government that has chosen an optimal transition policy avoid the temptation to deviate from it when enacting particular reforms? These important issues are beyond the scope of the present investigation. $^{20}$

\footnotetext{
${ }^{19}$ In my prior work, I have been quite explicit about how certain parts of my analysis depended on such assumptions - see, for example, Kaplow (1986, pp. 520-21, introducing the analysis of risk and incentives; section III.A, relaxing one of the assumptions; pp. 616-17, reemphasizing the role of assumptions in the conclusion) - although my work is not always thus interpreted.

${ }^{20}$ For some analysis of them, see Kaplow (1986, section II.C.3; 1987, section 4.6). Regarding the most important of these questions in the long run, the commitment problem, two sorts of approaches are available. One involves formal institutional arrangements such as the use of constitutional requirements (for example, the requirement of compensation for takings) or other strategies taking advantage of the separation of powers (a legislature might impose a transition policy on an agency). Another relies more directly on the development of norms, deviation from which is understood to be improper (for example, arbitrary confiscation is widely thought to be illegitimate independent of specific constitutional constraints). For skepticism about the possibility of establishing such norms in the tax context, see Stark (1996).

By contrast, case-by-case transition policy is problematic, primarily because of the importance of ex ante incentive effects but also because it invites costly rent seeking and it may
} 
2. Underlying substantive policy. - In much of the analysis, notably, in section $\mathrm{V}$, it will be assumed that underlying substantive government policy, including reforms thereof, is optimally determined. This assumption is important because, as will be seen, whether the incentive effects of various transition policies are beneficial or detrimental will sometimes depend on the desirability of the underlying reform. This is because transition mitigation tends to reduce the impact of new policies. When new policies are efficient, this effect of transition mitigation tends to be inefficient. Likewise, when reform is undesirable, transition relief that tends to undermine the effects of reform is beneficial. Consider, for example, delayed implementation, a common form of transition relief; an infinite delay would be ideal if the reform itself were deleterious, but such a delay would be absurd if the reform were valuable. ${ }^{21}$

In addition, it will provisionally be assumed that transition policy does not affect what substantive policy will be chosen. To an extent, this is a corollary of the preceding assumption, for a government actor presumed to make optimal decisions regarding reforms would not generally be influenced by the transition regime, although such influences are clearly possible. ${ }^{22}$ As will be explored in section VI, however, it is entirely possible that the transition policy that governments will have to follow may affect which underlying substantive reforms are implemented.

involve inferior risk mitigation (due to uncertainty about the extent of mitigation that will ultimately be provided by the government).

${ }^{21}$ In considering political reality, it may be noted that the present assumption that the reforms themselves are desirable will have some tendency to correspond to the perceptions of the relevant government actors. For example, a legislature is unlikely to be inclined to adopt transition rules that undermine the very policy it seeks to implement (although transition rules may be imposed as a constraint, such as when they are constitutionally required or when strong norms or procedures favor particular approaches).

${ }^{22}$ For example, a reform that was only moderately desirable if implemented optimally might be undesirable if required to be implemented under a sufficiently poor transition regime.

Transition policy may also influence optimal policy indirectly because transition policy influences ex ante investments, which in turn may influence what substantive policy is optimal ex post. Blume and Rubinfeld (1984, pp. 622-23) discuss this problem with regard to takings: In the absence of a requirement of compensation, investors might have incentives to overbuild (rather than the ordinary incentive to build less, as discussed in section V) because it will be optimal for the government to take parcels that are relatively less developed. But this argument is incomplete. Most obviously, overbuilding is a two-edged sword since, if the parcel is taken in any event, one loses even more. Furthermore, takings are usually employed to assemble large blocks of land, such as for rights of way, so it seems unlikely that an individual investor building more on a single plot would affect the project decision, though perhaps a slightly different route might be chosen. See Kaplow (1986, p. 568 n.168). Even more so, other government regulation tends to apply to classes of activity rather than to that of a single individual. (For another instance in which compensation for takings may affect ex ante investments in a manner that influences the desirability of takings, see note 95 on the case of endangered species preservation.) 


\section{B. Distinctions Among Types of Reforms and Effects}

Although section II emphasizes that there are important similarities among a variety of transition contexts, the problem is sufficiently broad and the types of government policies are sufficiently diverse that one can hardly expect the analysis to be the same in every instance. Here, a number of important distinctions are noted. Others will emerge throughout the rest of the analysis and in the applications, but even then the list will not be exhaustive.

1. Incidental versus intentional redistribution. ${ }^{23}$ - Transition policy is generally understood to concern gains and losses that are incidental to the underlying substantive reform rather than its object. For example, investors whose portfolios are disproportionately allocated to health sector stocks may be winners or losers when health policy is reformed, but this is unlikely to be the (or an) object of the reform. Thus, it is conceivable that one would favor the reform and yet support taxation of the winners or compensation of the losers. By contrast, a tax increase focused on the rich, designed to increase the extent of redistribution, is by design one that makes rich taxpayers losers. The notion that these losers should be compensated for their losses would be nonsensical, given the purposes of the reform. ${ }^{24}$

2. Accounting changes versus intended incentive effects. ${ }^{25}$ - One might raise or lower a tax, subsidy, or fine on a given activity in order to influence its extent, such as when taxing polluting activities or subsidizing expenditures on research and development. But there also can be mere accounting or other technical changes which, if unaccompanied by relief, can have powerful unintended effects. Suppose, for example, that taxation is to be changed from a fiscal year of July 1 to June 30 to a calendar year basis. If the change is made effective immediately, then there will be a six-month period of activity that either will be double taxed (counted as part of a year under both the old and new systems) or effectively exempt from taxation (being excluded from the final year under the old system and not included under the first year under the new system). Such an effect is unlikely to be intended and, if anticipated, can have huge incentive effects: The prospect of double taxation would tend to move significant economic activity out of the pertinent six-month period, whereas the prospect of exemption would cause

${ }^{23}$ See Kaplow (1986, p. 519 \& n.20, pp. 579-80; 1987, section 4.9); Samuels (1974). The distinction is less clear when a transition or proposed transition mitigation has a systematic distributive effect. However, it is generally better to address concerns about the income distribution through the rate structure of the income tax, transfer programs, and the like rather than skewing other policies on account of their distributive effects. See, for example, Kaplow and Shavell (1994).

${ }^{24}$ It should be apparent that incidental and intentional distributive effects are not selfdefining natural categories but rather depend upon the purposes of reforms and one's underlying objectives, particularly distributive objectives.

${ }^{25}$ See Kaplow (1986, subsection IV.C.3.b; 1987, subsection V.4.1). See also Shaviro (2000, pp. 53-62) (describing this distinction as one between "policy change retroactive taxes" and "accounting change retroactive taxes"). As discussed in section VII.D, this issue has most frequently been addressed in connection with the transition from an income tax to a consumption tax. 
much activity to be transferred into that period. Various adjustments (such as running the old or new regime with a six-month transition "year") could avoid such effects entirely.

3. Rules that regulate behavior versus default rules. ${ }^{26}$ - When discussing legal rules, most analysts have in mind rules that are binding, or at least that subject violators to fines or fees that are not optional. Yet important bodies of law, especially contract law (and related areas, such as aspects of commercial and corporate law), serve primarily to provide default rules, the purpose of which is to save parties the expense of making extensive provisions in their contracts and to save parties and adjudicators dispute resolution costs when no express provision has been made. Reform of default rules may well reflect new information as to which practices most parties would prefer rather than an attempt to reward or punish particular behavior.

In such cases, determining appropriate transition rules reflects different concerns from those to be examined in sections V and VI. On one hand, retroactive application may seem appropriate, if the default rule is seen as a guess - the best guess - of what most parties would have wanted to govern their affairs. On the other hand, prospective application is favored by the fact that parties for whom the prevailing default rule was substantially undesirable may have contracted around it, whereas parties would not have undertaken the expense to contract around default rules not yet in existence. Of course, legal change always may be anticipated, but with regard to default rules, where a significant purpose is to save parties the expense of providing for various unlikely contingencies, the possibility of anticipation may be of little consolation. These considerations also suggest that it may well not be optimal to change default rules very frequently, perhaps allowing less-than-ideal but not terribly inefficient default rules to remain on the books because parties are used to them and have adjusted their contracting practices accordingly.

\section{Private Actors: Incentives and Risk}

This section examines how various forms of transition relief affect the efficiency of private actors' behavior and the risk that they bear. ${ }^{27}$ The main analysis is presented in section A, which assumes that underlying government policy is optimal and unaffected by the form of transition relief (as does the remainder of section $\mathrm{V}$ ), that moral hazard is the only relevant market imperfection, and that relief is in the form of compensation for losses and taxation for gains. Section B considers additional market imperfections, and section $\mathrm{C}$ discusses the similarities and differences among different forms of transition relief.

${ }^{26}$ See Kaplow (1986, p. 598 n.275; 2000, p. 518).

${ }^{27}$ This section draws on the more extensive informal discussion in Kaplow (1986) and the formal analysis in Kaplow (1987, 1991a, 1992a). In addition to more through discussions and consideration of a broader array of factors, references to the pertinent literature on insurance and other matters can be found therein. For subsequent work in a similar spirit, see Shaviro (2000, ch. 3). 


\section{A. Basic Analysis}

1. Analogy between government-created risk and risk due to market or natural forces. ${ }^{28}$ - In the present setting, where the focus is on private actors and government substantive policy is taken to be optimal, government-created risk and risk due to market or natural forces, as well as government mitigation of such risk, are almost precisely analogous. To private parties, gains are gains, losses are losses, and taxation and compensation of gains and losses have the same cost or benefit regardless of the original source of the effects being mitigated. Likewise, market relief for risk - whether through explicit insurance arrangements or implicitly, such as through diversified financial ownership - is in principle equally effective regardless the source of the risk.

Because of the analogy between government risk and that due to market or natural forces, it is possible to analyze the transition problem by first examining the more familiar and straightforward problem of whether the government should provide relief for natural disasters, as is done in subsection 2, and then in subsection 3 to explain more fully how that analysis applies with regard to transition policy.

\section{Illustration of inefficiency of government relief using natural disaster analogy. ${ }^{29}$} (a) Incentive effects. - To see the implications of government relief in a simple, clear, and familiar setting, consider relief for natural disasters, such as flooding. The prospect of floods say, due to the periodic overflow of rivers or coastal storms - should lead actors to invest less than they otherwise would in areas prone to flooding because of the probability that their investments will be damaged or destroyed. And, in the absence of the prospect of compensation or other relief, they will be led to do so in a manner that tends to be efficient: The greater the risk of loss, the less they will invest. On the other hand, to the extent that losses will be compensated by the government, actors will not bear all of their losses (but will continue to reap the gains when there is no flood), creating an externality of sorts. Hence, they will overinvest.

(b) Risk, incentives, and market versus government mitigation of risk. - If it is efficient ever to invest in such regions, as it surely is in many cases, actors will bear risk. Some actors, such as large entities with dispersed ownership, will be approximately risk neutral. (It is difficult to overemphasize the importance of this point, for many government policies, ranging from large portions of the fields of taxation and regulation to trade policy, have a substantial portion of their effects on large corporations. ${ }^{30}$ ) Others, notably individuals, will be risk averse.

${ }^{28}$ In addition to my own work, which presents extensive analysis of private actors' risk and incentives based on the analogy between government and market risks, others have suggested the relevance of the analogy. See, for example, Graetz (1977, pp. 65-66), Hale (1927, pp. 528-29), Michelman (1967, pp. 1216-17), and Samuels (1974, pp. 113, 118, 124).

${ }^{29}$ See Kaplow (1991a) and also Arnott and Stiglitz (1991).

${ }^{30}$ Accordingly, many of the market imperfections discussed in section B will be irrelevant because they are inapplicable to risk mitigation through broad ownership. Another point is that some entities - like nonprofit organizations and lower-level units of government - are in this 
In the absence of government relief, risk-averse actors will be inclined to buy insurance. Insurance, however, can create adverse incentives - referred to as moral hazard - because once insulated from losses individuals have less incentive to avoid them. But there are ways to combat moral hazard.

First, when investment levels are observable, as they are in the present setting, moral hazard might be avoided entirely by making insurance premiums a function of the investment level. Individuals can invest more on flood plains, but they must pay for the greater expected losses covered by insurance up front, through higher premiums. In this manner, they can obtain complete insurance without there being any adverse incentive effect. ${ }^{31}$

Second, when observing investment or other behavior is not possible (and when other strategies fail ${ }^{32}$ ), a compromise will usually be optimal, one that involves partial coverage. The greater the coverage, the greater the incentive problem but the less risk is borne. Generally, the optimum will involve a compromise in such circumstances. (The reason this is so is that riskbearing costs are declining at the margin as coverage increases, whereas incentive costs will tend to be increasing at the margin.)

Might government disaster relief be efficient, or perhaps neutral, when individuals are risk averse? In this basic case, no. First, any relief offered by the government could be provided by the market. If it is not, under the present assumptions that will be because such relief is inefficient, taking into account both risk and incentive considerations.

Second, government relief tends to interfere with the efficiency of private risk mitigation. When investment levels are observable, private insurance permits full risk mitigation at no cost in terms of incentives. But if some or all losses are covered by government relief, individuals will invest excessively in high-risk areas.

respect similar to diversified firms.

${ }^{31}$ In the present setting, moral hazard is easy to combat directly because it involves a larger investment that both is easily observable and will only be insured if the individual seeks greater coverage. More subtle moral hazard problems, such as with property insurance, can often be dealt with in part through inspections (for smoke detectors or fireproof doors) and through policy exclusions (such as policies that cover rain damage to the interior of a building only if a storm broke through windows or walls but not if windows were left open). In other instances, such as the following illustration in the text involving product hazards, an insurer may have difficulty assessing an insured's efforts to reduce risks.

${ }^{32}$ See the previous footnote. In addition, when not all relevant behavior can be observed (perhaps the size of a building can be observed but not all aspects of construction or operation that influence the extent of losses in a flood), there is another, more subtle way that moral hazard can be avoided: by making coverage dependent on the state of nature rather than on the extent of actual loss. For example, compensation might be made a function of how high the water rises. Individuals would then have an incentive to take full precautions because, at the margin, any reduction in their actual losses does not reduce their insurance payment. 
Furthermore, even when individuals must bear some risk because insurance cannot fully combat moral hazard, government relief will be inefficient. The reason is that, to the extent of government relief, individuals (and their insurers) will simply ignore the portion of losses that is to be compensated. This will lead to excessive investment and also, in the aggregate, overinsurance.

To see this, suppose that it would be optimal for individuals to have obtained coverage for $50 \%$ of losses, this representing the point of the optimal risk-incentive tradeoff. Suppose further that the government were to compensate $50 \%$ of losses. This might seem to have the same effect as private insurance in the same amount, but this is not the case. Under such a regime of government compensation, individuals will be induced to purchase supplemental private insurance. This will, just as with pure private insurance, result in further inefficient overinvestment. The difference, however, is that as investment increases in the government compensation regime, $50 \%$ of any additional losses in the event of a flood are borne by the government, not by the insurer (who in turn would have charged the individual for this incremental cost through higher premiums). Because this portion of the loss is an externality as far as the individual and insurer are concerned, it will be ignored in fashioning their private arrangements.

This point, it should be clear, is general: As long as the government provides for compensation of any portion of losses, that portion is no longer a cost to private actors and hence will be ignored, resulting in overinvestment.

3. Application of analysis to transition mitigation. - Because government-created risk is analogous in relevant respects to market and natural risks and because government mitigation of gains and losses is inefficient with regard to the latter, it follows that it must be inefficient with regard to the former. Indeed, the same analysis is applicable. The only subtlety concerns the understanding of the nature of the adverse incentive effect in various transition settings. ${ }^{33}$

Consider, for example, a government decision to tax, limit the use of, or ban a product because it is learned that the product is harmful. The prospect of such reform will, in the absence of relief, discourage investment in producing the product; the greater the probability that the product will turn out to be harmful, the greater the resulting disincentive. It should be apparent that this incentive effect is desirable: It is a consequence of actors bearing the full costs and benefits of their actions. Likewise, to the extent that relief for transition losses is anticipated, actors ex ante will not expect to bear all of their losses and hence will invest excessively, just like prospective investors in regions prone to flooding. Furthermore, the analysis of risk, insurance, and so forth is essentially the same as in the previous case.

Consider another example: government takings, in particular, the prospect that land will

\footnotetext{
${ }^{33}$ For further discussion of this issue, see subsection 6.
} 
be taken for a highway, requiring the leveling of any buildings thereon. ${ }^{34}$ Again, the greater the probability that a highway will be built, the more likely that any building will, from that point forward, prove to be worthless. The prospect of compensation will lead to excessive construction on such sites. And so forth.

Indeed, similar incentive effects can be identified with regard to a wide range of government reforms. Reducing trade barriers or deregulation may reduce the value of inefficient production facilities that become exposed to competition. Or shifts in government spending priorities, away from programs or technologies that are no longer the most effective, will reduce returns to investments that are less in demand. In all of these cases, however, the changes indicate a real reduction in the value of such investments, so it would be optimal for the possibility of reform to be taken into account ex ante. To the extent that transition relief is expected to be provided, this will not occur. In each instance, to be sure, the possibility of reform that is unaccompanied by relief will impose risk, but the analysis of the general superiority of market risk mitigation remains applicable.

In sum, just as in the case of market and natural risks, the prospect of government transition mitigation creates an externality in private actors' decisionmaking that would not otherwise exist. This suggests that, with regard to the efficiency of private actors' behavior, no relief tends to be optimal, and considerations of risk bearing do not upset this conclusion in the setting under consideration.

4. Mitigation of gains. - Similarly, if one instead considered an example involving gains - so-called "windfalls" - the effect of government mitigation, now taxation, would be to induce inefficiently low investment. Because a portion of the upside of any investment would be absorbed by the government, while leaving the individual to bear the full up-front cost of the investment, too little investment will occur. Likewise, private arrangements would produce an optimal risk-incentive tradeoff, as long as no government mitigation was expected to be forthcoming.

To illustrate, suppose that a new subsidy is enacted for a particular field of research deemed to be more important in light of heightened terrorist threats. Mitigation might involve taxing away the benefits of such a subsidy to those already engaged in the research or using grandfathering to limit the benefits of the subsidy to new ventures. It should be recognized, however, that such mitigation of gains has adverse ex ante incentive effects. In essence, such an

${ }^{34}$ The first significant publication analyzing the incentive issue in the takings context is Blume, Rubinfeld, and Shapiro (1984), which largely ignores considerations of risk. (Adverse incentive effects of compensation were previously recognized by Baxter and Altree (1972) in a related context.) Contemporaneously, Blume and Rubinfeld (1984) present a favorable view of compensation for takings because of risk considerations, downplaying the incentives issue. Neither article attempts to synthesize these opposing points in a single, comprehensive analysis. More broadly, this shortcoming illustrates the need to offer an integrated analysis of risk and incentives rather than examining each in isolation. 
approach takes away some of the upside return to valuable research in precisely the states of the world in which it proves to be most valuable. By contrast, if such new subsidies were to be made broadly available, the anticipation of such a transition policy would lead to more of such research ex ante, thus efficiently promoting the purpose of the new subsidy policy. (Consider a firm deciding whether to invest heavily ex ante. It will reason that if the terrorist threat increases, it will benefit significantly such as through government rewards, but that if on account of its foresight it will not receive such benefits, their being focused on those who are induced to increase investment after the fact, the firm will not be as inclined to make significant investments ex ante.)

5. The possible need for retroactive application. ${ }^{35}$ - Sometimes efficiency in the present setting requires not only that no government mitigation be provided but also that a reform be made explicitly retroactive. Consider again the example involving the decision to tax, limit, or ban a product that turns out to be hazardous. If the hazard has always been present - just previously unknown to the government regulator due to its inevitably incomplete information it would have been optimal for production to be even lower ex ante, reflecting the harm caused throughout the life of the product. A general policy of full retroactive application in such contexts - for example, imposing legal liability or a retroactive tax applicable to harm caused prior to the reform - would accomplish this because the anticipation of such a transition rule would lead producers to take into account the full harm that their products may cause. Nominally prospective application, by contrast, induces them to consider only harm that occurs after the government discovers and acts on a problem. ${ }^{36}$

In this setting, it is necessary to distinguish reform motivated by new information about existing conditions, as in the foregoing example, from reform motivated by changed circumstances. For example, if the harm is not to health but rather that a product causes electronic interference with a new technology, then full retroactive application would not create the appropriate ex ante incentives; rather, the anticipation of such a transition policy would excessively discourage investment, which in this case does not cause any harm prior to the emergence of the new technology. If the harm will occur only in the future, a product ban that takes effect when the harm will begin to occur, for instance, is sufficient to alleviate any problem.

${ }^{35}$ See Kaplow (1986, section II.C.1; 1987, section 3.2).

${ }^{36}$ The analysis in the text does not assume that the actor has full knowledge ex ante that the product is hazardous. Even if the actor knows that its product is hazardous with a probability - which may be the best estimate then available - full retroactivity will tend to produce the correct incentive: The greater the probability that the product is harmful, the less of it will be produced. Furthermore, the anticipation of retroactive application would also provide proper incentives to inquire further into the likelihood that the product is dangerous and into ways to mitigate the harm if the product turns out to be unsafe. 
6. Comment on incentive effects, with special reference to tax reform. ${ }^{37}$ - The analysis of transition policy is often elusive because the efficiency consequences of incentive effects are often subtle and sometimes nonexistent. When a reform involves banning a dangerous product, taxing sources of pollution, and the like, the social benefit from anticipatory incentives (assuming the reform is a good one) is tangible and clear. For some policy changes, including many reforms of details of the tax system, the efficiency consequences may be less apparent. Thus, if depreciation schedules are modified or accounting rules jiggled, it may not be obvious in terms of consequences in the real economy - why such change is desirable (if indeed it is).

Usually, one can make analogies to corrective (Pigouvian) taxes and subsidies: Activities should be penalized or rewarded depending on the existence of divergences between social and private costs and benefits. Likewise, reforms may be due to new information about activities, changes in circumstances, or a recognition that previous analysis was mistaken. Thus, repeal of a tax subsidy may reflect a new understanding about the merits of the subsidized activity or about how the existing subsidy operates (perhaps the fact that it was a de facto subsidy was not appreciated). For example, when it makes sense to repeal a tax subsidy, the efficiency gain arises from the real benefits of the shift in investment, and the benefits of not providing transition relief are due to less distortion prior to the reform, to the extent that the reform and lack of relief in the event of reform are anticipated. ${ }^{38}$ Importantly, the efficiency gain is not due to the fact that more revenue might be collected in the absence of transition relief. ${ }^{39}$

Relatedly, one cannot compare transition regimes using revenue costs as the metric. It is sometimes suggested that, if the target is taken to be achieving a given level of incentive effect over a pertinent time period, the revenue cost will be no lower if subsidy repeals are not accompanied by transition relief because higher up-front subsidy levels will be required instead. ${ }^{40}$ But this assumes that the efficiency question is concerned with revenue cost and that the resulting effect on behavior is given and implicitly irrelevant to the social calculus. Such an approach is incorrect. Rather, the efficiency effect concerns precisely the level of the pertinent behavior. Furthermore, it is incorrect (really, internally inconsistent) to assume that the correct level of activity into the future is given and known ex ante and, in particular, is unaffected by the prospect of subsequent reform that itself is motivated by the discovery of new information that

${ }^{37}$ In prior writing, I noted this point briefly, see Kaplow (1986, p. 556 n.134), and in hindsight without sufficient emphasis or elaboration.

${ }^{38}$ Accordingly, the view that requiring transition relief cannot impede efficient reform because the government should be willing to make the reform even if it must compensate losers in some manner - see, for example, Ramseyer and Nakazato (1989, p. 1169) - misses the point. As explained earlier in section A, it is the anticipation of such relief that causes the distortion, and the distortion in question concerns ex ante investment. This distortion arises when transition mitigation is anticipated even if the provision of such relief is not expected to have any effect on what reforms are ultimately adopted.

${ }^{39}$ See the discussion of revenue effects in note 7.

${ }^{40}$ See, for example, Graetz (1977, pp. 68-73), Logue (1996, pp. 1138-43), Ramseyer and Nakazato (1989, p. 1167). 
indicates the error in prior understanding of the situation. (For some further elaboration, see subsection C.3, on grandfathering implicit in program design.)

\section{B. Additional Market Imperfections ${ }^{41}$}

Moral hazard, forming the core of the incentives analysis in section A, is often the most important market imperfection with regard to mitigating risk, and as the foregoing discussion suggests government mitigation rather than curing the problem only makes matters worse. This section considers some additional market imperfections, ones that may sometimes warrant government action, but not necessarily in the form of traditional transition mitigation. In addition, it should be kept in mind that, in principle, each of the imperfections considered may be applicable to market and natural risks as well as to government risks; hence, if there is a basis for government mitigation, it will a priori exist for all types of risks (though context-specific factors could make the case for government mitigation stronger or weaker in one or another particular setting). ${ }^{42}$

1. Adverse selection. - Adverse selection may arise when two conditions are simultaneously present. First, potential insured parties must have different probabilities of suffering harm (or, with gains, receiving benefits). Second, these differences must be known to individuals but unobservable to insurers (or other financiers who may be involved in the diversification of risk). In such cases, at a given premium, insurance will tend to be most attractive to higher-risk individuals. Because insurers cannot observe who in fact poses a higher risk, they cannot charge differential premiums. Hence, they must simply assume that they are attracting only higher-risk individuals and accordingly charge higher premiums. But at higher premiums, the pool who choose to insure will further narrow, leaving only those with the highest of risks. And so forth. The result is that many may find insurance unattractive - even though at actuarially fair rates some coverage would be efficient - and it is possible for insurance markets to unravel altogether. ${ }^{43}$

Adverse selection is unlikely to be important in most transition settings because neither of the two necessary conditions holds. First, because government policies tend to be uniformly applicable, it is unlikely that different actors will have different probabilities of being subject to a reform. Second, even when such differences do exist - perhaps a reform will be limited to a particular industry - it seems unlikely that this would be both known to the private actors and

\footnotetext{
${ }^{41}$ For further discussion, see Kaplow (1986, subsections II.B.2-II.B.4; 1987, sections 4.14.5).

${ }^{42}$ Keep in mind that this section $\mathrm{V}$ assumes the optimality of underlying government behavior and its being unaffected by transition policy. As I emphasized in my prior work, for example, Kaplow (1986, p. 534), an important exception to the presumption of similarity of market and government risks concerns issues of government behavior, considered here in section VI.

${ }^{43}$ The famous and now-familiar analogy involves the used car market (the "market for lemons") analyzed by Akerlof (1970).
} 
unknown to the insurers and other financiers who specialize in dealing with actors in that industry. ${ }^{44}$

In some cases, however, adverse selection may be important. For example, regarding the regulation of hazardous products, firms will tend to know more about hidden dangers of their own, perhaps unique products than insurers. (Of course, firms are often widely held, reducing or eliminating the need for insurance.) When adverse selection is important, compulsory insurance and related policies may be efficient. ${ }^{45}$

2. Administrative costs. - Different forms of risk mitigation may involve different administrative costs for a variety of reasons. Some systematic differences among classes of mechanisms should be noted. First, most private mechanisms, like insurance, are arranged ex ante, while most forms of government relief are applied ex post. Especially for reforms having a low ex ante probability, this favors government relief because administrative costs need only be incurred in the event that a reform actually occurs. Two countervailing factors are that ex ante provision can be wholesale - for example, wide ownership simultaneously diversifies all sources of risk, and a single insurance policy can cover losses from many sources - and that it may reduce dispute resolution costs, by agreeing on the amount of or formula for compensation in advance.

Another set of differences arises among government transition mechanisms. Notably, taxation and compensation require individualized assessments of gains and losses whereas grandfathering and delayed or partial implementation do not, although the latter may involve complexities of their own in determining eligible assets or dealing with multiple rules for longer periods of time.

3. Imperfect information by private actors. - Private actors may be uninformed about or misperceive the probability of various risks. For example, there is evidence that individuals underestimate the likelihood of serious floods, leading to overinvestment and underinsurance. ${ }^{46}$ This problem would seem to be more important for individuals than firms and for those relying on insurance rather than broad ownership to mitigate risk. Government mitigation may less

${ }^{44}$ It is possible that some firms might secretly find out about impending government action before such news becomes public, upon which they would attempt to take out large insurance policies. In settings where this is likely, one might expect there to be delays in coverage taking effect or a temporary reluctance of insurers to offer new policies.

${ }^{45}$ In the present example involving hazardous products, the moral hazard that would arise may well be too great in most settings to justify substantial protection. Note also that adverse selection involving government transitions is no different in terms of the optimality of government relief than adverse selection in other contexts. Thus, government relief - essentially a form of compulsory insurance, but without premiums paid by insureds (which, as explained earlier, can be important with regard to incentives) - is likely to be efficient if but only if more general government finance and insurance of various market actors tends to be efficient.

${ }^{46}$ See, for example, Kunreuther et al. (1978). 
distort incentives in such cases and provide valuable protection against risk. However, in such cases compulsory insurance has an advantage on incentive grounds: For example, forcing individuals to purchase properly priced flood insurance will avoid overinvestment despite probability misperceptions because the risk of loss will be reflected in insurance premiums, which themselves will be a function of individuals' investment decisions.

\section{Different Forms of Transition Mitigation ${ }^{47}$}

The foregoing discussion focused on compensation and taxation as means of mitigating transition losses and gains. Other important mechanisms are grandfathering (exempting preenactment investments from reforms) and partial or delayed implementation, phase-ins being a combination of these latter approaches. Although different techniques are more commonly used in some contexts than others and some commentators seem to favor or oppose certain methods as a matter of principle, there is an important commonality among all these approaches, as explained in subsection 1. Subsection 2 identifies the most important differences, which derive from incentive effects. ${ }^{48}$ Subsections 3 and 4 consider two important variations.

1. Similarities. - For any given reform and investment, each transition mechanism will give some level of relief. For example, grandfathering may provide full relief, ${ }^{49}$ and delayed implementation of five years may provide significant partial relief (the extent depending on the remaining life of the pre-enactment investment). Whatever the level of relief, however, one can consider an equivalent degree of compensation of losses and taxation of gains. As a first approximation, the effects with regard to both incentives and risk bearing should be the same.

2. Differences. - Nevertheless, there are important differences among the mechanisms. Compensation and taxation provide relief, but it is confined to pre-enactment investment and furthermore the relief is monetary rather than in-kind. Both of these features can be advantageous. Consider, for example, a ban of a hazardous product. Though compensation has adverse effects on ex ante incentives as explored in section A, at least upon enactment the product will no longer be produced by old producers or new ones.

Grandfathering, by contrast, would allow old producers to continue production. Delayed and partial implementation both allow adverse effects of pre-enactment investment to continue -

${ }^{47}$ For more detailed analysis of the similarities and differences among transition mechanisms, see Kaplow (1986, section IV.A; 1987, section 3.1). For further discussion of alternative transition mechanisms, with an emphasis on the tax context, see Shaviro (2000, ch. 11) and, on the relevance of adjustment costs, see Zodrow (1985).

${ }^{48}$ See also subsection B.2 on administrative cost differences.

${ }^{49}$ As Graetz (1977, pp. 60-63) and others have noted, grandfathering can provide more than complete relief; that is, a transition loss might actually become a gain under full grandfathering. The reason is due to scarcity effects. For example, if a product ban were implemented but applicable only to new manufacturers, existing manufacturers might gain from being protected against additional competition. 
for a period of time or to some degree - and also provide some escape for new investment as well. $^{50}$ Thus, for a given level of relief, delayed and partial implementation are worse than grandfathering, which in turn is worse than compensation in such cases. As between delayed and partial implementation giving similar amounts of relief, partial (immediate) implementation will often be preferable because many reforms may be subject to diminishing returns. ${ }^{51}$ The desirability of phase-ins, a combination of delayed and partial implementation, falls in between.

Outside the takings context, compensation (and taxation of gains) is rarely employed. Grandfathering (sometimes partial, such as when it lasts only for a period of time or fails to provide complete exemption), delayed and partial implementation, and phase-ins are common. This suggests that when transition mitigation is optimal - or when it will be employed despite its inefficiency, due to political forces - there may remain significant opportunities for improvement by selecting forms of mitigation that provide equivalent protection in a less inefficient manner.

3. Variation: grandfathering implicit in program design. ${ }^{52}-$ It is possible to embed transition mitigation, notably, a form of grandfathering, in program design. Suppose, for example, that a subsidy of $\$ 100$ per year is under consideration for certain investments that have a life of 10 years. Grandfathering in the event of repeal would involve continuing to provide the subsidy for preexisting investment. Instead, however, the entire subsidy could have been provided up-front; perhaps an initial subsidy of $\$ 800$ (with no subsequent payments) would have a present value equivalent to being entitled to $\$ 100$ per year for 10 years. With the up-front subsidy, no explicit grandfathering would be required in the event of repeal. If one instead wished to achieve a result equivalent to immediate, full implementation of repeal without any grandfathering, it would be necessary to tax back an amount equal to the present value of $\$ 100$ per year for the remaining years of any particular investment. ${ }^{53}$ Under present assumptions,

${ }^{50}$ This escape can be especially large if, for example, the delay applies not just to old investments (actually, a combination of delay and grandfathering) but also to post-enactment investments because the latter may accelerate to qualify for more favorable pre-reform treatment (especially if pre-effective-date investment is itself to be grandfathered rather than subject to the new regime once the effective date passes).

${ }^{51}$ See Zodrow (1981). To elaborate, the optimal level of a reform (say, the optimal extent of a tax or subsidy on an activity) will ordinarily be at the point where marginal benefits equal marginal costs. If marginal benefits are falling and marginal costs rising (in the opposite case, one would certainly not be at the optimum), then the marginal net benefits of the reform are falling in the relevant range, reaching zero at the optimum. Partial immediate implementation, say at a level of $90 \%$, would not reduce the net benefits by $10 \%$ but rather by a smaller, possibly very small, amount (because marginal net benefits are so small near the optimum). By contrast, a delay sufficient to provide $10 \%$ protection for pre-enactment investors would, roughly, scale back the total costs and benefits, and hence the total net benefit, by $10 \%$.

${ }^{52}$ See Kaplow (1986, section IV.A.2.b; 1987, section 5.3). See also the discussion in subsection A.6.

${ }^{53}$ Another way that grandfathering implicit in program design can be made equivalent to no grandfathering would be for the amount of the up-front subsidy - now assumed not to be 
where transition policies are anticipated ex ante and consistently implemented ex post, it does not matter which approach is employed as long as they are done equivalently and properly.

The ability to incorporate transition mitigation in program design raises the question of how one can tell when this occurs. That is, how does one distinguish an initial subsidy of $\$ 800$ that is really an implicit grandfathering of a $\$ 100$ per year subsidy from a simple subsidy of $\$ 800$ ? The answer is to be found in the purpose of the program, which is to say the reason for creating the incentive. A government believing that a type of investment generates a positive externality of $\$ 100$ per year would wish in principle to provide a $\$ 100$ per year subsidy. In this manner, the subsidy would be contingent on the investment continuing to exist. Such a subsidy would be repealed if, say, due to changed circumstances, the positive externality no longer existed. By contrast, suppose that the positive externality were due to the very act of creating the asset and that this externality was $\$ 800$. Then an up-front subsidy of $\$ 800$ would be appropriate.

4. Variation: relief limited to uninsured losses.$^{54}$ - Some forms of government mitigation, typically for disasters rather than for government action, provide relief that is limited to uninsured losses. ${ }^{55}$ Examples include some specific assistance programs - a notable example being the government compensation fund for families with relatives who died as a result of the September 11 terrorist acts - as well as provisions of the income tax under which uninsured losses from a variety of casualties are deductible, thus providing relief proportional to one's marginal tax rate.

This form of relief, which appears to be designed to mitigate risk, can have the opposite effect if it is anticipated ex ante. Specifically, private insurance is discouraged. For example, if an actor anticipates that $50 \%$ of uninsured losses will be compensated, then for every additional dollar of insurance coverage that he purchases, he will have to pay a premium reflecting the full expected cost of such coverage, but he will simultaneously be forfeiting $50 \%$ coverage of that dollar loss, which would have been available for free. In essence, the individual is paying full price at the margin for half protection (since the other half of losses is already covered). ${ }^{56}$ This effect - inducing inefficiently low aggregate mitigation of risk - is the opposite of the result with ordinary transition relief, which as explained tends to result in excessive mitigation of risk. In

taxed back - to be reduced in magnitude so that it equaled not the present value of the subsidy continuing for the life of the investment but instead the present value of the subsidy discounted for the probability and timing of repeal under the annual subsidy version. (Such a subsidy, to have the stated effect, may have to be modified regularly as the probability and expected time to reform changed.)

${ }^{54}$ See Kaplow (1991b, 1992b).

${ }^{55}$ Private relief, notably, through charitable organizations, is often limited, implicitly or explicitly, to uninsured losses and thus has similar effects to this form of government relief.

${ }^{56}$ Similar inefficiencies can arise in more subtle ways. For example, if transition relief is more likely if losses will be incurred by ordinary individuals rather than by widely held corporations, there is an incentive for assets subject to transition risk to be held by individuals, who are more risk averse. See Kaplow (1986, p. 597). 
the absence of offsetting market imperfections, both deviations tend to be inefficient.

\section{Government Behavior}

As highlighted in the introduction and in my prior work on the subject, ${ }^{57}$ the analysis of government behavior - the optimality of underlying substantive policies and reforms and how they may be influenced by transition policy - is of central importance in the assessment of transition policy. ${ }^{58}$ Because the subject of government behavior is so vast and complex (and, quite frankly, because it is not an area I have studied in depth), the remarks in this section will largely be suggestive. Hopefully, they will help clarify some of the relevant questions and lines of analysis and also indicate a number of useful avenues for further research.

\section{A. Optimality of Government Policy: Overview}

1. Analysis of government behavior. ${ }^{59}$ - In the foregoing discussion, it was largely assumed that the government behaves optimally, in terms of maximizing social welfare, and furthermore is not influenced in its underlying policy choices by the transition policy that is in force. In a complete analysis, one would relax these assumptions and consider when government policy is indeed optimal, how in particular it deviates from optimality when it is not, and how in turn transition policy would affect the choice of underlying substantive policies. Also relevant would be the rent-seeking costs involved in the political process and how these costs may be influenced by transition policy. ${ }^{60}$ Such is the subject of an entire discipline, political science (or, as some prefer, political economy or public choice), and is obviously beyond the scope of this investigation. ${ }^{61}$

A more complete analysis of government behavior might well be expected to generate different conclusions in different settings, which in turn suggests an important set of reasons that optimal transition policies may vary by context. Taxation, tort law, and tariffs, not to mention countless other areas of law and regulation that raise transition issues, may differ along a number of important dimensions that are relevant to a political analysis: type of government actor (legislature, agency, or court), level of government (local, state, federal, or international

${ }^{57}$ See note 19.

${ }^{58}$ This point has also been emphasized in some subsequent work on transition policy, see, for example, Ramseyer and Nakazato (1989) and Shaviro (2000, ch. 4), and has been a theme in much (but not all) of the literature on compensation for takings. See sources cited in note 94.

${ }^{59}$ Government behavior regarding transition policy itself is addressed in subsection IV.A.1.

${ }^{60}$ Going further, one could undertake a positive analysis attempting to explain what transition policies will in fact be employed in contrast to the present article which is concerned with the normative assessment of transition policy.

${ }^{61}$ Seminal modern works include Downs (1957), Buchanan and Tullock (1962), Olson (1965), and Niskanen (1971). More recent works are Buchanan, Tollison, and Tullock (1980), Ordeshook (1986), Mueller (1989, 1997), and Alt and Shepsle (1990). 
negotiation), concentration of gains and losses, level of organization of private actors, and so forth. In section B, the analysis will usually be crude (often of a "black-box" sort) and the illustrations merely suggestive; no attempt is made to get to the bottom of these matters in any particular situation, much less in general.

2. Applicability of analysis of private actors when government policy is not optimal. Although in section $\mathrm{V}$ it was assumed that underlying government policy was optimal, much of the analysis is relevant even when it is not. Certainly the positive analysis of how private actors would behave and of the risk they would bear is largely independent of whether the government reforms they predict or are subject to are welfare maximizing.

The main point at which the optimality of government policy is relevant involves assessment of the efficiency of ex ante incentive effects. For example, failure to provide relief to manufacturers when their product is banned will discourage production of the product ex ante. This effect is desirable if the product is banned when in fact it is found to be dangerous. But if it is a beneficial product that will be banned, the reduction in ex ante production is counterproductive.

Two reservations should be noted. First, to an extent discouraging ex ante investment may still be advantageous. If, once the product is banned, certain capital will become less valuable, it is better that less of it be created ex ante regardless of whether the decision to ban the product is a good one. (That there will be less of the product produced ex ante would, as noted, be undesirable.) ${ }^{62}$ Furthermore, a policy can be inefficient in ways that are largely unrelated to the desirability of ex ante incentive effects. For example, a new regulation may be clumsy in terms of administrability or impose excessive costs (such as when particular technologies are mandated rather then providing incentives that induce private actors to minimize costs), yet the problem being regulated may be real.

Second, even if government often makes mistakes, it may nevertheless be true that it is right more often than not. In such cases, the efficiency consequences of ex ante effects on investment will, on average, be as stated, although to a lesser degree. ${ }^{63}$ Of course, it may be best to have a transition policy implied by the analysis in section $\mathrm{V}$ when reforms are desirable but to have transition policies that maximally undermine reforms (for example, infinitely delayed

${ }^{62}$ Takings offers a stark example. If a building will be destroyed to build a highway, its value is lost (and to precisely the same extent) regardless of whether the highway should have been built.

${ }^{63}$ Some of the effects would be desirable, others undesirable, with the net favoring the former. Taking the argument to the limit, if on average reforms were a matter of indifference whether random or the result of political forces that have random effects on the public goodthen whether or not transition policy enhanced the effectiveness of reforms or inhibited them would make little direct difference. Such a view is suggested by Ramseyer and Nakazato (1989) with regard to tax reforms (though they further argue in favor of transition relief due to the belief that it tends to reduce rent seeking, on which see subsection B.6 and note 86). 
implementation) when they are undesirable. However, it seems farfetched to suppose that such a transition policy would be feasible. If government could be counted on to make the correct determination about desirability of reform and also to act on it in setting transition policy, one might expect it to be able to make the right reform decision in the first place.

\section{B. Effects of Transition Policy on Government Behavior ${ }^{64}$}

This section briefly considers some ways that transition policy may affect underlying government behavior. When transition policy has such effects, different transition policies may be optimal than otherwise, but in considering the optimal transition policy it should be kept in mind, as just noted, that some of the analysis in section V of private actors' incentives and riskbearing may remain applicable.

1. Bilateral torts analogy. ${ }^{65}$ - Bilateral torts involve potential accident situations where the behavior of both injurer and victim affect the probability of loss. Strict liability provides the injurer with proper incentives (the prospect of harm is fully internalized) but the victim with none (since it does not bear any loss). No liability provides the victim with proper incentives (it bears the full loss) but the injurer with none. One might allow a defense to strict liability of contributory negligence (to preserve victims' incentives) or utilize a negligence rule (which gives the injurer an incentive that, if successful, leaves victims bearing losses, giving them an incentive as well). Both compromises require a determination of the optimality of at least one party's behavior - victims in the case of contributory negligence and injurers in the case of negligence - which is both costly and subject to error.

The analogy is that full compensation (like strict liability) destroys private actors' (victims') incentives whereas no compensation, while preserving private actors' incentives, leaves the government (injurer) with no financial incentive. As with tort liability, one could consider compromises. Victims' compensation could be conditioned on the optimality of their ex ante investment decisions, which it would seem would be most difficult to determine. Or the government's obligation to pay compensation could be dependent on the suboptimality of its behavior. When the government's behavior is assumed to be optimal, as in section $\mathrm{V}$, then only victims' behavior needs to be controlled and a regime of no compensation tends to be efficient. Alternatively, one could attempt to motivate a regime of no compensation on the view that, whatever means exist to determine the optimality of government behavior, they are employed in policymaking itself; put another way, if there were a means of identifying suboptimal government policy, it would seem better to use the information directly to modify government policy rather than to leave bad policy in place and use the information as the basis for awarding

${ }^{64}$ See Kaplow (1986, section III.A; 1987, sections $4.7 \& 4.8 ; 2000$, section 13 ).

${ }^{65}$ On bilateral torts, see Brown (1973) and Shavell (1987). For application to transitions generally, see Kaplow (1986, 569 n.174; 1987, subsection 4.7.1), and to takings in particular, see Blume, Rubinfeld, and Shapiro (1984) and Miceli and Segerson (1996, pp. 54-55). 
compensation. $^{66}$

The benefit of this analogy is that it highlights the problem of government behavior and, in particular, suggests that it may be responsive to incentives, notably, to those that may be provided by transition relief. The difficulty is that the analogy on the government side is highly imperfect because analysis of government behavior differs from that of private behavior (even if ultimately it is rooted in similar first principles). ${ }^{67}$ Many differences will emerge in the subsequent discussion, most directly in the next subsection.

2. Fiscal illusion. - The fiscal illusion argument, most often advanced in the takings context, ${ }^{68}$ is closely related to the foregoing torts analogy (though it is not usually cast in those terms). The claim is that, because the government does not actually bear the cost of its actions, it will be prone to excessive takings; requiring compensation internalizes this cost, thus correcting the problem.

On its face, this argument is incomplete, for the government ordinarily does not actually receive the benefits of its actions either. Hence, in the absence of a compensation requirement, it is not obvious whether the government will give too little or too much relative weight to costs. Likewise, a requirement of compensation results in the government bearing all the costs and none of the benefits, which might on this view be expected to lead to decisions heavily skewed toward inactivity. ${ }^{6}$

To advance the analysis, a more nuanced account of government behavior is required. Under one view, costs or benefits will be given greater weight if they are more concentrated because those who bear them will better be able to overcome the free-rider problem that impedes political mobilization. ${ }^{70}$ Since in the takings context it is costs that are usually more

\footnotetext{
${ }^{66} \mathrm{An}$ important caveat, related to the analysis in the next subsection, is that if the prospect of compensation would itself induce better government behavior, then using the information to determine compensation may have the same effect as using it directly to correct policy errors.

${ }^{67}$ This point is also emphasized by Fischel and Sykes (1999) in their consideration of whether the government should be held to the same contract rules as private parties.

${ }^{68}$ See most of the references cited in note 94.

${ }^{69}$ See, for example, Quinn and Trebilcock (1982, p. 135). Consistent application of the logic behind the fiscal illusion argument would seem to favor not only requiring compensation but also taxation of all benefits from government activity. Compare Bell and Parchomovsky's (2001b) discussion of takings and "givings." Note that if the extent of losses and benefits could reliably be assessed, such information could be used to determine the correct government policy, dispensing with the payment of compensation and collection of taxes, which has the advantage of saving administrative costs and of avoiding adverse incentive effects on private behavior. Note further, however, that systems of compensation and taxation will motivate parties to provide information - that is to litigate - about the true extent of costs and benefits, although that itself a costly process. See Kaplow (1987, section 4.7.1).

${ }^{70}$ See, for example, Downs (1957) and Olson (1965).
} 
concentrated, this view suggests that costs will be given too much weight, not too little. Indeed, a compensation requirement might result in more takings because, once compensation is required, costs are dispersed broadly among taxpayers so political opposition might be diffused. $^{71}$

Under another view, government entities' power, prestige, and ability to benefit from perquisites is positively related to the size of their budget. ${ }^{72}$ Hence, an agency that had to provide compensation might gain thereby, and once compensation was required, it would have perhaps a greater incentive to increase the scope of its activities. On the other hand, the enhanced visibility of its actions and political difficulties in competing for funding might reduce its activity.

Yet another set of possibilities is that government actors may benefit from greater activity per se or that, due to weak incentives for performance, they may be too inertial. In the former case, a compensation requirement may provide a useful corrective, whereas in the latter case it may exacerbate the problem.

Clearly, the simple fiscal illusion argument is inadequate. Determining whether requiring compensation, taxation of gains, and other forms of transition relief will increase or reduce the extent of certain types of policies, and assessing the social desirability of any such effects on government policymaking, requires more explicit theoretical and empirical analysis of the pertinent government actors. Moreover, once the question of the quality of government decisionmaking is explicitly presented, analysis of how to improve it should not be confined to transition mitigation.

3. Tyranny of the majority; abuse of power-Democratic systems do not necessarily produce socially desirable outcomes. Indeed, there are systematic reasons to be concerned about abuse. One problem is simply that, in the absence of constraints, a majority may benefit itself at the expense of a minority, even when the costs to the latter exceed the benefits to the former. ${ }^{73}$ Likewise, both legislatures and government officials can abuse their power by singling out

\footnotetext{
${ }^{71}$ This point illustrates the argument in subsection 5 on the use of transition relief enhancing the feasibility of reform by buying off opposition. Empirical evidence on the actual effects of compensation is limited. Cordes and Weisbrod (1979) find that federal highway funding tended to shift toward states with lower compensation requirements, supporting the view that requiring compensation reduces activity, albeit in a context where the contrary political considerations seem less applicable.

${ }^{72}$ See, for example, Niskanen (1971).

${ }^{73}$ This problem, that a majority each member of which benefits slightly outvotes a minority each member of which suffers greatly, is in a sense opposite to the aforementioned point that concentrated losses may be overweighted in the political process because such losers are better able to organize than a large number of individuals each of whom benefits little. Which phenomenon is more important obviously depends on the political context; each outcome may sometimes occur in different domains.
} 
particular individuals or groups (despised minorities, political opponents, those unwilling to pay for protection) for adverse treatment or by bestowing government largesse on a select few.

Transition mitigation - such as proscriptions of retroactive legislation, requirements of compensation - can in some cases help to alleviate such problems. ${ }^{74}$ There are, however, limits on what can be accomplished because it is necessary to devise ways (constitutional requirements, strong social norms) to ensure that protective transition rules can be enforced in such circumstances. Furthermore, it seems difficult to tailor these mechanisms to the particular problem. If the protections are reasonably narrow, there may be many ways to circumvent them. ${ }^{75}$ A physical taking may give rise to a right to compensation, but a similar extraction through various regulations may not. On the other hand, if protections are sufficiently broad so as to make essentially impossible any sort of redistribution, virtually all government policy may be thwarted, including both policies aimed at improving efficiency and those designed to accomplish what many may view as legitimate distributive objectives. ${ }^{76}$

Given the importance of this problem, it should hardly be ruled out a priori that some transition rules may have a useful role to play. Furthermore, as a historical matter, constitutional restrictions on ex post facto legislation and bills of attainder and the takings clause may best be explained by the sorts of concerns considered here.

4. Expropriation; capital levies. - A particular type of government abuse involves expropriation, which is all the more worrisome because of its enticing features. A familiar lesson of public economics is that a one-time capital levy - in which the entire capital stock is taken by the government, accompanied by a promise never to do it again - is an efficient tax. Substantial revenue is raised, largely from the rich, and no future distortion, notably, of savings and investment decisions, occurs if the promise is believed. Moreover, as long as the expropriation is not anticipated, there are no adverse ex ante incentive effects. Consequently, such taxation - and likewise retroactive taxation more generally (on a one-time, never-again basis) - at first seems appealing. ${ }^{77}$

The difficulty with the argument is obvious. As has long been recognized, a government that behaves this way may not be trusted in the future, with serious adverse effects on

${ }^{74}$ Such considerations in part motivate Epstein's (1985) views on takings, compensation, and redistribution.

${ }^{75}$ Consider, for example, the limited effectiveness of the equal protection clause with respect to economic regulation (that is, outside areas in which heightened scrutiny is applied).

${ }^{76}$ Epstein (1985) is favorably disposed toward such an outcome, though truly binding prohibitions on any even incidental redistribution would tend to make even limited government infeasible. Much of the argument about takings doctrine and about limited government is concerned with making workable distinctions in this realm. The controversy concerns not only how to draw lines but which activities of government are permissible in principle.

${ }^{77}$ Levmore (1993) thereby presents a more favorable view than is conventional toward retroactive taxation. 
incentives. ${ }^{78}$ Consider the example of governments in developing countries that are thought to pose expropriation risks, whether for foreign investors, who are led to avoid the country, or for domestic wealthholders, who attempt to transfer assets abroad. Successful governments need to find ways - whether through constitutional constraints or established norms - of committing themselves not to engage in such behavior. Indeed, one suspects that there is a broad understanding that any government that engages in such activity will not be trusted again any time soon, such that the future cost from lack of investment exceeds the (possibly substantial) short-run gain from a capital levy.

For such restraints to succeed, however, it is necessary that expropriation be distinguishable from ordinary government policy reform, which often creates some losers. An important difference is that, as suggested by the analysis in section $\mathrm{V}$, the anticipation of reform - and its concomitant incentive effects - is ordinarily desirable, whereas with a capital levy anticipation would be undesirable. ${ }^{79}$ Thus, for example, an anticipated policy of the government seizing assets that are dangerous or are used to commit crimes will discourage acquisition of such assets, which would be desirable, whereas an anticipated policy of seizing all capital would discourage productivity generally.

5. Political feasibility - Transition relief is sometimes favored because it reduces opposition to desirable reforms. ${ }^{80}$ For example, those who have paid dearly for valuable licenses in industries with restricted entry (often on the secondary market, as with taxi owners and broadcasters) may strongly resist efficient deregulation, but compensation may reduce or eliminate their resistence. (Observe that private insurance may also produce a similar effect, although the analysis is more complex. ${ }^{81}$ )

${ }^{78}$ Compare the discussion in subsection IV.A. 1 of the difficulty of the government announcing one transition policy and following another.

${ }^{79} \mathrm{~A}$ complete analysis is more involved because redistributive taxation generally has the character that ex ante incentive effects are undesirable. Notably, a labor income tax (or a consumption tax) inefficiently distorts the labor-leisure choice. Here, the relevant analysis seems to be whether a redistributive tax is desirable even taking ex ante incentive effects into account. A government acts consistently and thus may maintain credibility if it limits itself to taxes that meet such a criterion. Some important possible tax reforms (including the enactment of new taxes) do raise important questions involving expropriation. See, for example, the discussion of the transition from an income tax to a consumption tax in section VII.D (and of other tax transitions in note 101) and the discussion of accounting changes in subsection IV.B.2.

${ }^{80}$ See, for example, Tullock (1978) and Usher (1995). For further exploration between compensation and the prospects of legal change, see Levmore (1999).

${ }^{81}$ Individuals whose losses were covered by insurance would be less inclined to resist reforms causing the losses. On the other hand, their insurers would now have an incentive to lobby. Moreover, insurers, by aggregating claims, may have more concentrated interests and thus be more effective. In addition, insurance companies may often work together and are organized as a group for other purposes. On the other hand, insurance companies may sometimes be less effective lobbyists, in part because they may generate less sympathy than 
In addition to distorting private actors' ex ante investment decisions, this approach has two problems. First, why should it be assumed that relief will buy off opposition to desirable reforms rather than opposition to undesirable reforms? There is some basis for a positive view: Desirable reforms will have benefits in excess of their costs; if all losers were compensated and individuals still favored the reform, it will tend to be a desirable one. With an undesirable reform, whose costs exceeded its benefits, it would not be possible thus to compensate fully all losers. The concern, however, is that only politically influential losers - of both good and bad reforms - would actually be compensated in the political process. ${ }^{82}$ Again, a more complete analysis is required. Essentially, the present discussion indicates that political side payments, however provided, should be viewed as forms of transition relief, suggesting that many of the other issues raised here would be relevant.

Second, there are ex ante political incentives to consider. Special interests already have excessive incentives to lobby for favorable treatment. If the norm is that, if and when such benefits are repealed, the special interests will be compensated or otherwise protected, then their initial incentive to lobby for such policies will be increased. ${ }^{83}$ It is not obvious that the net effect of buying off opposition ex post, when one includes effects of undesirable policies ex ante and wasteful rent-seeking expenditures, would be positive.

6. Rent seeking - The prospect of reform may be accompanied by rent-seeking behavior, such as when private interests expend resources lobbying. ${ }^{84}$ The most important consideration with regard to such behavior is how it affects the quality of the resulting legal regime, a subject identified in subsection A.1, further analysis of which is beyond the scope of this article.

Nevertheless, it is worth considering quite briefly how transition policy may affect overall expenditures on rent-seeking activity, a lesser but not unimportant concern. Ramseyer and Nakazato (1989) argue that guaranteeing transition relief in advance will reduce rent-seeking activity regarding repeals, although this very fact will make legislatures disinclined to promise such protection. ${ }^{85}$ As suggested in subsection 5, however, promises of protection ex post make special interest legislation more attractive ex ante, which will increase rent-seeking activity

would their insureds if personally bearing the losses and in part because of jurisdictional differences (for example, homeowners who oppose a zoning ordinance that would reduce their property values may be politically effective at the local level of government, whereas an out-ofjurisdiction insurance company owned by numerous anonymous investors may have less clout).

${ }^{82}$ For concerns about the related process of logrolling, see, for example, Buchanan and Tullock (1962) and Mueller (1979).

${ }^{83}$ See, for example, Kitch (1977), Quinn and Trebilcock (1982), and McKenzie (1986).

${ }^{84}$ See Doernberg and McChesney (1987).

${ }^{85}$ Epstein's (1985) argument favoring restrictive takings law is interpreted by Merrill (1986) as grounded in significant part on the fact that such a regime, with its requirement of compensation, will reduce rent seeking. See the related discussion of tyranny of the majority in subsection 3 and also subsections 2 and 5 on how providing compensation may make government activity easier by diffusing political opposition. 
surrounding original enactments. ${ }^{86}$

A further point about any link between transition policy and rent seeking is that legislatures can always use substitute means to extract rents from an interest group. ${ }^{87}$ For example, if the legislature was constrained from repealing a specific tax break for the oil industry - which it might like to threaten to do in order to extract rents from industry lobbyists - it could always instead threaten to impose some other new tax adjustment or regulation having a similar effect.

In sum, how various transition policies would affect the extent of rent seeking (and, more importantly, its effects on policy implementation) is a complex question deserving of further study.

7. Binding future regimes. - Transition policy also affects the ability of a given government to bind future regimes. If current enactments can simply be repealed by a subsequent government regime, policy may tend to fluctuate more rapidly, which will have some undesirable consequences independent of which policies actually are best. ${ }^{88}$ But if current enactments are costly to repeal or their effects cannot fully be reversed because of a requirement of transition relief (for example, a norm of compensation or grandfathering), then a given regime can project its policies into the future, after they have been rejected by the electorate. ${ }^{89}$

Moreover, there may be ex ante incentives to design policies that increase lock-in effects. This will, however, tend to be true whatever is the transition policy, although it would seem more difficult to lock policies in when transition mitigation requirements are lower. (See also

${ }^{86}$ Ramseyer and Nakazato (1989, p. 1173) acknowledge this phenomenon but dismiss it because the degree of ex ante benefit to be enacted is taken as given in their discussion. Yet in an analysis in which all subsequent legislation is assumed to be an endogenous product of lobbying, it is inconsistent to ignore lobbying at the outset on the ground that the legislature implicitly will act identically regardless of what lobbying occurs. For skepticism about Ramseyer and Nakazato's claim, see Fischel and Sykes (1999, pp. 378-79).

${ }^{87}$ See, for example, Ramseyer and Nakazato (1989, p. 1172 n.48).

${ }^{88}$ Consider, on one hand, alternating every year between two policies and, on the other hand, always being subject to the average (in some sense) of the two policies. The latter will probably involve reduced transaction and administrative costs and also tend to discourage moving economic activity across years for the purposes of taking advantage of whichever regime is more desirable.

When a polity is rather evenly divided - which is when frequent fluctuations in ruling parties are most likely to occur - a number of factors tend to produce moderation, including each party's' ever-present incentive to appeal to the median voter and, relatedly, parties' desires to maintain a ruling majority and succeed at reelection.

${ }^{89}$ Other means, such as undertaking durable public investment projects or engaging in long-term contracting, tend to have a similar effect. See Glazer (1989), Laffont and Tirole (1993, ch. 16), and Wickelgren (2001). 
the discussion in subsection V.C.3 on grandfathering implicit in program design and in section VII.E on government contracting. $)^{90}$

\section{Applications}

It is helpful briefly to consider some applications to make the analysis concrete. Also, by considering a range of contexts, one can see both how the same analytical framework is of quite general use and how it nevertheless may lead to different conclusions in different contexts. ${ }^{91}$ An important caveat, though obvious, is worth emphasizing: None of the discussions that follow purport to be comprehensive; not even close. In particular, the analysis of government behavior will often be highly incomplete.

\section{A. Regulation of Newly Discovered Externalities ${ }^{92}$}

Regulation of newly discovered externalities, such as by banning products or production processes, using corrective (Pigouvian) taxes and subsidies, or applying (extending) common law doctrines, tends to be desirable not only ex post but also with regard to its ex ante effects. As discussed in section $\mathrm{V}$, the anticipation of transition losses in the case of negative externalities will efficiently discourage (and of transition gains in the case of positive externalities will efficiently encourage) investment ex ante. Furthermore, as explained in subsection V.A.5, when the externality is preexisting (rather than due to changes in conditions that have given rise to an externality not previously present), retroactive application tends to be the efficient transition policy because the anticipation thereof will efficiently further affect production during the relevant period of time. ${ }^{93}$ Such transition policies also impose risk, but market mitigation tends to be best (transition risk not being significantly different from market and natural risks in relevant respects); furthermore, that most firms are widely owned is important to recognize.

Regarding government behavior, the relevant actor might be a legislature, an agency, or a court; obviously, different analyses may be appropriate in each case, both of the quality of policymaking regarding externalities and of whether different transition policies are likely to affect such policymaking, for better or worse. How such analysis would bear on the

\footnotetext{
${ }^{90}$ For some further discussion of this complex issue, see Kaplow (1986, subsection III.A.5; 1987, subsections 4.7.3 \& 5.3).

${ }^{91}$ The discussion in subsections IV.B.1 of incidental versus intentional redistribution and in IV.B.3 of rules that regulate behavior versus default rules reinforces the claim that a common conceptual framework, once clearly understood, can help to resolve some difficult issues and may readily lead to quite different results in different settings.

${ }^{92}$ See, for example, Kaplow (1986, subsection IV.C.1; 1987, section 5.1).

${ }^{93}$ In addition, the analysis in section V.C of the differences among transition mechanisms is applicable: All mechanisms except compensation of losses and taxation of gains may permit continued inefficiency regarding pre-enactment investment, and delayed, partial, and phased-in implementation may sacrifice benefits regarding post-enactment behavior.
} 
applicability of the foregoing treatment of private actors' incentives would depend in part on the nature of the reform. For example, if production is disallowed or sufficiently discouraged with the result that industry-specific assets lose value, the prospect of this loss should ideally be taken into account ex ante even if the policy causing the loss is mistaken. But the efficiency of other incentive effects may well depend on whether the underlying government policy is correct.

\section{B. Takings $^{94}$}

Takings were often used in section $\mathrm{V}$ to illustrate the analysis of private actors and in section VI on government behavior. When takings result in the destruction of existing assets, such as when a building is leveled to construct a highway, ${ }^{95}$ it is optimal for investors to take such losses into account regardless of whether the taking is desirable. ${ }^{96}$ This transition policy does result in private actors bearing risk, but market risk mitigation tends to be more efficient than compensation (although various imperfections noted in section V.B might qualify this conclusion).$^{97}$ On the other hand, retroactive application would ordinarily be unnecessary because takings of this sort, even when optimally chosen, do not indicate that ex ante investments were undesirable per se..$^{98}$

A number of (conflicting) views regarding the effect of a compensation requirement on government behavior were offered. Much further analysis and empirical study is necessary to resolve the issue. It should be noted, however, that concerns for abuse of power do seem stronger than average in some classic takings contexts, in which an individual's or a small group's assets are singled out by the government, and this problem may explain the existence of

${ }^{94}$ See, for example, Bell and Parchomovsky (2001a, 2001b), Blume and Rubinfeld (1984), Blume, Rubinfeld, and Shapiro (1984), Epstein (1985), Farber (1992), Fischel (1995), Fischel and Shapiro (1989), Hermalin (1995), Kaplow (1986, subsection IV.C.2; Kaplow 1987, section 5.2), Miceli and Segerson (1996), Michelman (1967).

${ }^{95}$ The analysis differs when private investments enhance the public use, such as when land is taken to further species preservation. Then, private actors need to be induced ex ante to maintain such investments rather than to reduce them (for example, by clear-cutting a forest, the public use value may be destroyed, which benefits the private actor if this reduces the likelihood of a taking that will not be fully compensated). See, for example, Innes (2000).

${ }^{96}$ Because losers will often be individuals, who may, for example, misperceive risk, the analysis is not straightforward, although the prior framework (see especially section V.B) indicates how such complications should be taken into account.

${ }^{97}$ As further explained in section V.B, when imperfections (other than moral hazard) interfere with market risk mitigation, compulsory insurance may nevertheless be superior to compensation or other government mitigation on incentive grounds, but may be worse with regard to administrative costs.

${ }^{98}$ Although beyond the scope of the present article, the framework offered here also helps to illuminate when the government should acquire property by takings and when it should engage in ordinary purchases. See Kaplow (1986, pp. 529-30 n.54, 605-06 n.300; 1987, p. 189 n.160). 
constitutional protections against uncompensated takings. In sum, as I emphasized when first writing on the subject, ${ }^{99}$ the resolution of many of the relevant arguments is quite uncertain and some point in conflicting directions, so no simple conclusion may be offered.

\section{Electric Utility Deregulation ${ }^{100}$}

Electric utility deregulation might in some cases be expected to result in large gains (when price ceilings are lifted) and in others to cause large losses (when inefficient sources of production are no longer protected against competition from lower-cost power generators). Much of the analysis in sections V and VI seems applicable. For example, utilities that do not expect transition mitigation - either taxation of gains or compensation for losses - would be more strongly encouraged ex ante to construct and maintain efficient sources of electricity but not costly ones. The ex ante incentive effect is likely to be particularly important in such a setting because deregulation has been a serious prospect for an extended period of time. The problem is complicated, however, by the fact that there is no clear ex ante understanding of what sort of transition mitigation might accompany deregulation

A significant complication in this setting involves the fact that private actors, here, electric utilities, are heavily regulated and thus not free ex ante to make their own decisions. For example, they may have been led to construct inefficient capacity by regulators. Of course, if it is anticipated that, if deregulation occurs, the utility will have to bear large losses, it would more strongly oppose such construction ex ante and regulators may find it more difficult to induce inefficient behavior. Whether this is the case depends on the power and behavior of the regulators, which requires further study.

Other important private actors are not so regulated. Notably, consumers (who make long-run investments regarding energy usage) and suppliers (particularly fuel companies) undertake ex ante behavior that may be affected by anticipated transition policy because it may be implemented through mechanisms (for example, energy taxes and subsidies) that influence the prices they would expect to pay or receive. This is another instance in which direct mitigation - such as through compensation for losses or taxation of gains, which has more of a lump-sum character and hence does not directly affect future behavior - may be more efficient than other forms of mitigation (holding the extent of mitigation constant).

${ }^{99}$ See, for example, Kaplow (1986, p. 606; 1987, p. 192).

${ }^{100}$ See, for example, Kaplow (1993) and also Kolbe, Tye, and Myers (1993) and Quinn and Trebilcock (1982) on regulatory risk more generally. 


\section{Transition from an Income Tax to a Consumption Tax ${ }^{101}$}

The transition from an income tax to a consumption tax presents an important illustration of accounting changes, addressed in subsection IV.B.2. Consider a dollar earned in the final period subject to an income tax, which the earner chooses to save. It will be taxed when earned, for that is what an income tax does. Suppose further that, in the first period under the consumption tax, this individual spends the dollar. This act will also result in full taxation, for a consumption tax applies to all expenditures, including those from savings. ${ }^{102}$ Indeed, this sort of transition, in the absence of any relief, involves a significant capital levy of the sort discussed in subsection VI.B.4. ${ }^{103}$ (Here, the expropriation is not complete. But if the tax rate is, say, 30\%, a very substantial portion of the capital stock will in essence have been taken by the government. ${ }^{104}$ )

${ }^{101}$ Early treatments (which do not rely on the qualitatively different ex ante incentive effects of accounting changes versus other changes) include Bradford and U.S. Treasury (1984, ch. 6) and Graetz (1977, pp. 50-52; 1979, pp. 1649-51, 1653-58). The present discussion follows Kaplow (1986, subsection IV.C.3.b; 1987, subsection 5.4.1; 1995a). See also Bradford (1996), Sarkar and Zodrow (1993), and Shaviro (2000, ch. 9). It should also be noted that similar analysis is applicable to a pure change in tax rates, especially rates on capital. Indeed, the transition from an income tax to a consumption tax is much like the introduction of a consumption tax or a rate increase on a consumption with regard to the treatment of preenactment savings, operating much like a partial capital levy. See also Kaplow (1987, section 5.4.2) regarding the need to change tax rates as revenue needs vary over time, the benefits of smoothing tax rates over time, and how transition mitigation relates thereto.

Another important tax transition - noted in Kaplow (1987, p. 201 n.172) - that has received some attention involves corporate income tax integration, the central issue being whether old equity should be permitted to gain or should be exempt from the benefits of such reform. See, for example, American Law Institute (1989, 1993), U.S. Treasury (1992), and Shaviro (2000, ch. 8). See also the discussion of the proposed recapture of benefits from accelerated depreciation in connection 1986 Tax Reform Act's reduction of the corporate tax rate in Kaplow (1987, subsection 5.4.2).

${ }^{102}$ For simplicity, the treatment of interest will be ignored. The treatment of interest is at the heart of the difference between an income tax and a consumption tax over the long run, but it is not central to the transition phenomenon considered in the text.

${ }^{103}$ Likewise, a gain is conferred on individuals who borrow pre-enactment in the absence of mitigation because borrowed principal is not taxable under an income tax but repayment of principal is deductible under a consumption tax; the ex ante disincentive to save discussed below is thus accompanied by a parallel ex ante incentive to borrow. See Kaplow (1995a, p. 1118), suggesting that transition treatment of basis should be provided for net basis, which is to say basis in pre-enactment assets net of pre-enactment liabilities.

${ }^{104}$ Some simulations of transitions to a consumption tax find large efficiency gains, much of which can be attributable to this capital levy effect. This is why transitions to a wage tax tend to show substantially lower levels of welfare than transitions to a consumption tax, even though the two taxes are equivalent in the long run. See, for example, Auerbach and Kotlikoff (1987, 
But it is not the purpose of moving to a consumption tax to expropriate a significant fraction of capital. Furthermore, if such a transition, without relief, is anticipated, one would expect substantial ex ante avoidance activity, notably dissaving and attempts to transfer capital outside the jurisdiction. ${ }^{105}$ As discussed in subsection IV.B.2, accounting adjustments seem appropriate in such cases. Here, one might exempt withdrawals of pre-enactment savings from consumption taxation or offer a similar level of relief in other forms. (The transition to a consumption tax also raises a number of other complex transition issues that are not considered here. ${ }^{106}$ )

\section{E. Government Contracting ${ }^{107}$}

Government contracting - a widespread activity ranging from the procurement of paperclips to the hiring of millions of workers and the commissioning of jet fighters, space probes, and elaborate highway projects - is related to the transition problem in a number of ways. First, many of the issues considered here could be applied to government contracting per se. Governments adopting new policies, such as new spending priorities, will change their contractual practices. Often this is simple: If fewer paperclips are needed under the new regime, fewer will be ordered. But this can be more complex, such as when the government has entered into a long-term contract to produce jet fighters but later decides to reduce defense expenditures. ${ }^{108}$

A number of observations are in order. One is that the government makes a choice, ex ante, whether to buy products on the spot market (probably the norm for paperclips) or enter into contracts of varying durations. Another is that most governments voluntarily subject themselves to ordinary contract liability. Hence, when they breach (say, due to a change in priorities), they pay damages. Whether this approach makes sense is a matter deserving analysis. ${ }^{109}$ Payments

ch. 5) and the discussion in Sarkar and Zodrow (1993).

${ }^{105}$ Indeed, that a transition to a consumption tax without relief involves a heavy tax on savings is antithetical to consumption tax proponents' belief that a major benefit of a consumption tax is that it, unlike an income tax, does not disadvantage savings.

${ }^{106}$ See, for example, Bradford (1996).

${ }^{107}$ The present discussion follows Kaplow (1986, pp. 529-30 n.54, 541-42 n.90, 564, 587; 1987, sections 5.3 \& 5.4.2; 2000, section 13). See also Fischel and Sykes (1999). In addition, there is an economic literature on government procurement that has some relevance. See, for example, Laffont and Tirole (1993).

${ }^{108}$ Another sort of complication arises from government regulation, such as when civil service rules protect government employees' jobs.

${ }^{109}$ And, as should be clear from the discussion to follow, the question of the government's choice of contract duration similarly warrants examination. On these and related questions, see, for example, Fischel and Sykes (1999) (noting that contract doctrine for the U.S. government differs from that for private contracts, suggesting that some of these special legal doctrines serve a useful function by limiting the ability of government to shield agreements due to rent seeking from subsequent attack), Laffont and Tirole (1993, ch. 16) (on whether the government's ability 
for breach (in all contract settings) may induce excessive reliance. ${ }^{110}$ On the other hand, they provide good incentives regarding breach and the absence of such payments may result in inefficiently little reliance investment. Of course, ordinary economic analysis of contracts considers private actors. When the government is a party, the question of how it behaves in general and how this behavior is affected by the prospect of having to pay damages is complicated, as discussed in section VI. ${ }^{111}$

Second, running the analysis in the opposite direction, many have suggested that government policy generally should be analogized to contracts, in which case any reform can be seen as a contract breach. ${ }^{112}$ There are a number of problems with this notion. Initially, as noted, it is not obvious that ordinary contract analysis is fully applicable when the government is a contracting party. Furthermore, legislation, regulation, and other government lawmaking is in important respects different from contracts precisely in that legal regimes explicitly contemplate change. ${ }^{113}$

Additionally, and relatedly, the government can be seen as making a choice when it decides to enact a law or regulation rather than enter into a contract. For example, it could choose to enact a subsidy of $\$ 100$ per year for a long-lived type of investment; such a subsidy, by its nature, might at some point be repealed. (Historically, most subsidies have ultimately been repealed or amended or expanded, often numerous times.) Or it could announce its willingness to enter into a contract with all comers (or some subset, just as eligibility for a subsidy might be limited by statute or regulation), under which it would bind itself to pay $\$ 100$

to bind future governments through long-term contracts is desirable), and Wickelgren (2001) (discussing how traditional contract damage remedies increase the incentive of incumbent governments to structure contracts to bind future governments). Also, compare the discussion in subsection VI.B.7 on how transition policy may affect the ability of a government to bind future regimes.

${ }^{110}$ See, for example, Shavell (1980) and Rogerson (1984).

${ }^{111}$ The analysis, of course, depends on which government actors are involved. It may be that some institutions, such as a legislature, an agency, or a court, would establish certain reputations regarding their future behavior, but that others may have greater difficulty doing so or convincing particular private actors that they are reliable. Accordingly, some government actors may find it advantageous to act through law and rely on their reputations regarding when and how reforms will be made and others may be better off entering into binding contracts.

${ }^{112}$ See, for example, Logue (1996, pp. 1143-49, 1183-86) and Ramseyer and Nakazato (1989, pp. 1166-71).

${ }^{113}$ Indeed, this point is reflected in Supreme Court contract clause doctrine. See, for example, National R.R. Passenger Corp. v. Atcheson, T. \& S.F. Ry., 470 U.S. 451, 465-66 (1985) (quoting Dodge v. Board of Educ., 302 U.S. 74, 79 (1937)) (“[A]bsent some clear indication that the legislature intends to bind itself contractually, the presumption is that 'a law is not intended to create private contractual or vested rights but merely declares a policy to be pursued until the legislature shall ordain otherwise.' . . Policies, unlike contracts, are inherently subject to revision and repeal. ..."). 
per year for a fixed term of years or for the life of the investment.

Much could be said about which approach makes more sense in a given instance, as suggested in part by the analysis in subsection V.C.3 of grandfathering implicit in program design. An important point to observe is that most legal regimes offer government actors a choice, one that can be exercised differently depending on the circumstances. ${ }^{114}$ If, instead, one insisted that all government policy be treated identically, as constituting a binding contract subject to certain contract rules, this flexibility would be lost.

Such a loss, however, may be meaningless, for statues, regulations, or court decisions could be made expressly conditional on future enactments; common boilerplate could be added in every instance, or a legislature or agency might simply enact an umbrella rule governing all of its other enactments. Indeed, one could characterize the status quo in such a manner. Another way to put the point is to view legislation and regulation as analogous to short-term or at-will contracts or to contracts that contain a termination provision that is invoked by government action following its ordinary lawmaking procedures. (In fact, a substantial portion of government contracting involves spot purchases or short-term agreements. ${ }^{115}$ )

Thus, for purposes of making an analogy between legal change and contracts, repeal can just as easily be understood as legitimate termination of one of the aforementioned contracts as it can be compared to a breach of a long-term contract that did not permit termination before the end of the term except upon payment of damages. That is, nothing in the contract analogy itself tells us what sort of contract - of what duration and with what provisions for termination, breach, and remedies - should be the subject of the analogy. To assume, perhaps implicitly, that the relevant analogy is to a long-term contract is to beg the question. ${ }^{116}$

\section{Conclusion}

The study of transition policy is receiving increasing attention from scholars in many fields of law, particularly takings and taxation. Given the ubiquity of the problem and commonalities across areas of application, even further attention - and cross-fertilization - is warranted.

\footnotetext{
${ }^{114}$ See note 111 suggesting one of the possible benefits of allowing different government actors to choose differently.

${ }^{115}$ Even long-term contracts, such as for a new type of fighter aircraft, may involve a prototype or a limited order, with subsequent, larger orders possibly being placed in the future, depending on the success of the contractor and the level of later defense needs.

${ }^{116}$ Furthermore, when explicit long-term contracts are made, an effective contracting agency will take into account the possibility that its needs may differ in the future and, even if the contract is not made freely terminable, it may scale down its demands accordingly. Compare the discussion in note 53 of adjusting the level of a subsidy when it is implicitly grandfathered by making it fully payable up front.
} 
The existing literature, however, in addition to emphasizing some legal subjects more than others, has been skewed in a number of respects. One is that far more attention has been given to transition losses than to transition gains despite the symmetry of the two phenomena. Another is that the analysis of private actors with regard to incentives and risk bearing is substantially more developed than is the analysis of government behavior, including how such behavior is affected by transition policy. In this instance, a good deal of attention has been devoted to the latter category of behavior, but the problem is more complex and most analysis including by this author - has been fairly black box and has not taken full advantage of recent decades of work by political scientists and other pertinent scholars. Also, there is a greater need for clear statements of the objective of transition policy (welfare is favored herein) and tracing effects directly; heavy use of proxies and intuitions is often problematic, and this is especially so with regard to transition policy, which involves a meta-question of sorts.

Finally, as emphasized in the introduction, it is important to make explicit and consistent assumptions when analyzing transition questions, especially regarding government behavior with regard to transition policy (including private actors' expectations thereof) and underlying substantive policy. It is often challenging enough to assess the welfare effects of various government reforms, such as in the area of tax policy. It is even more difficult to examine what policy should be toward future changes and, in particular, how the process of change itself should be addressed with regard to what is, at that moment, past behavior. As a first step, analysis must be clear and internally coherent. Ultimately, assumptions will hopefully become more realistic. Further questions regarding implementation of transition policy must also be addressed. Taken together, such research should enhance the understanding of existing government transition policy and hopefully allow for its improvement. 


\section{References}

Akerlof, George (1970), "The Market for Lemons: Quality Uncertainty and the Market Mechanism," Quarterly Journal of Economics 84, 488-500.

Alt, James E. and Shepsle, Kenneth A., eds. (1990), Perspectives on Positive Political Economy, Cambridge: Cambridge University Press.

American Law Institute (1989), Federal Income Tax Project, Reporter's Study Draft Subchapter C (Supplemental Study) Distributions, William D. Andrews, reporter, Philadelphia: American Law Institute.

American Law Institute (1993), Federal Income Tax Project, Integration of the Individual and Corporate Income Taxes, Reporter's Study of Corporate Integration, Alvin C. Warren, Jr., reporter, Philadelphia: American Law Institute.

Arnott, Richard and Stiglitz, Joseph E. (1991), "Moral Hazard and Nonmarket Institutions:

Dysfunctional Crowding Out or Peer Monitoring?," American Economic Review 81, 179-190.

Auerbach, Alan J. and Hassett, Kevin A. (2001), "Tax Policy and Horizontal Equity," in Hassett, Kevin A. and Hubbard, R. Glenn (eds.), Inequality and Tax Policy, Washington, D.C.: AEI Press.

Auerbach, Alan J. and Kotlikoff, Laurence J. (1987), Dynamic Fiscal Policy, Cambridge: Cambridge University Press.

Baxter, William F. and Altree, Lillian R. (1972), "Legal Aspects of Airport Noise," Journal of Law and Economics 15, 1-113.

Bell, Abraham and Parchomovsky, Gideon (2001a), “Takings Reassessed," Virginia Law Review 87, 277-318.

Bell, Abraham and Parchomovsky, Gideon (2001b), "Givings," Yale Law Journal 111, 547-618. Blume, Lawrence and Rubinfeld, Daniel L. (1984), "Compensation for Takings: An Economic Analysis," California Law Review 72, 569-628.

Blume, Lawrence, Rubinfeld, Daniel L. and Shapiro, Perry (1984), "The Taking of Land: When Should Compensation be Paid?," Quarterly Journal of Economics 99, 71-92.

Bradford, David F. (1996), "Consumption Taxes: Some Fundamental Transition Issues," in Boskin, Michael J. (ed.), Frontiers of Tax Reform, Stanford: Hoover Institution Press.

Bradford, David F. and U.S. Treasury Tax Policy Staff (1984, 2d ed.), Blueprints for Basic Tax Reform, Arlington, VA: Tax Analysts.

Brown, John P. (1973), "Toward an Economic Theory of Liability," Journal of Legal Studies 2, 323-350.

Buchanan, James M., Tollison, Robert D. and Tullock, Gordon, eds. (1980), Toward a Theory of the Rent-Seeking Society, College Station: Texas A\&M University Press.

Buchanan, James M. and Tullock, Gordon (1962), The Calculus of Consent, Ann Arbor: University of Michigan Press.

Cordes, Joseph J. and Weisbrod, Burton A. (1979), "Governmental Behavior in Response to Compensation Requirements," Journal of Public Economics 11, 47-58.

Doernberg, Richard L. and McChesney, Fred S. (1987), "On the Accelerating Rate and Decreasing Durability of Tax Reform," Minnesota Law Review 71, 913-962.

Downs, Anthony (1957), An Economic Theory of Democracy, New York: Harper.

Epstein, Richard A. (1985), Takings: Private Property and the Power of Eminent Domain, Cambridge, MA: Harvard University Press. 
Farber, Daniel A. (1992), "Economic Analysis and Just Compensation," International Review of Law and Economics 12, 125-138.

Feldstein, Martin (1976), "On the Theory of Tax Reform," Journal of Public Economics 6, 77104.

Fisch, Jill E. (1997), "Retroactivity and Legal Change: An Equilibrium Approach," Harvard Law Review 110, 1055-1123.

Fischel, Daniel R. and Sykes, Alan O. (1999), "Government Liability for Breach of Contract," American Law and Economics Review 1, 313-385.

Fischel, William A. (1995), Regulatory Takings: Law, Economics, and Politics, Cambridge, MA: Harvard University Press.

Fischel, William A. and Shapiro, Perry (1989), “A Constitutional Choice Model of Compensation for Takings," International Review of Law and Economics 9, 115-128.

Glazer, Amihai (1989), "Politics and the Choice of Durability," American Economic Review 79, 1207-1213.

Graetz, Michael J. (1977), "Legal Transitions: The Case of Retroactivity in Income Tax Revision," University of Pennsylvania Law Review 126, 47-87.

Graetz, Michael J. (1979), “ Implementing a Progressive Consumption Tax,” Harvard Law Review 92, 1575-1661.

Hale, Robert L. (1927), "Value and Vested Rights," Columbia Law Review 27, 523-529.

Hermalin, Benjamin E. (1995), "An Economic Analysis of Takings," Journal of Law, Economics, \& Organization 11, 64-86.

Innes, Robert (2000), "The Economics of Takings and Compensation When Land and Its Public Use Value Are in Private Hands," Land Economics 76, 195-212.

Kaplow, Louis (1986), “An Economic Analysis of Legal Transitions,” Harvard Law Review 99, 509-617.

Kaplow, Louis (1987), Optimal Transition Policy: Replacing Horizontal Equity With an Ex Ante Incentives Perspective, dissertation accepted by Harvard University Department of Economics, Cambridge, MA.

Kaplow, Louis (1989), "Horizontal Equity: Measures in Search of a Principle," National Tax Journal 42, 139-154.

Kaplow, Louis (1991a), "Incentives and Government Relief for Risk," Journal of Risk and Uncertainty 4, 167-175.

Kaplow, Louis (1991b), "The Income Tax as Insurance: The Casualty Loss and Medical Expense Deductions and the Exclusion of Medical Insurance Premiums," California Law Review 79, 1485-1510.

Kaplow, Louis (1992a), "Government Relief for Risk Associated with Government Action," Scandinavian Journal of Economics 94, 525-541.

Kaplow, Louis (1992b), "Income Tax Deductions for Losses as Insurance," American Economic Review 82, 1013-1017.

Kaplow, Louis (1993), “An Ex Ante Perspective on Deregulation, Viewed Ex Post," Resource and Energy Economics 15, 153-173.

Kaplow, Louis (1995a), "Recovery of Pre-Enactment Basis Under a Consumption Tax: The USA Tax System,” Tax Notes 68, 1109-1118.

Kaplow, Louis (1995b), “A Fundamental Objection to Tax Equity Norms: A Call for Utilitarianism," National Tax Journal 48, 497-514. 
Kaplow, Louis (1996), "The Optimal Supply of Public Goods and the Distortionary Cost of Taxation," National Tax Journal 48, 513-533.

Kaplow, Louis (2000), "General Characteristics of Rules," in Bouckaert \& DeGeest (eds.), Encyclopedia of Law and Economics, vol. V, pp. 502-528, Cheltenham, UK: Edward Elgar (also electronically published at http://encyclo.findlaw.com).

Kaplow, Louis (2001), "Commentary on Tax Policy and Horizontal Equity," in Hassett, Kevin A. and Hubbard, R. Glenn (eds.), Inequality and Tax Policy, Washington, D.C.: AEI Press.

Kaplow, Louis, and Shavell, Steven (1994), "Why the Legal System Is Less Efficient than the Income Tax in Redistributing Income," Journal of Legal Studies 23, 667-681.

Kaplow, Louis, and Shavell, Steven (2002), Fairness versus Welfare, Cambridge, MA: Harvard University Press.

King, Mervyn (1983), “An Index of Inequality: With Applications to Horizontal Equity and Social Mobility," Econometrica 51, 99-115.

Kitch, Edmund W. (1977), "Can We Buy Our Way Out of Harmful Regulation?," in Martin, Donald L. and Schwartz, Warren F. (eds.), Deregulating American Industry: Legal and Economic Problems, Lexington, MA: Lexington Books.

Kolbe, A. Lawrence, Tye, William B. and Myers, Stewart C. (1993), Regulatory Risk: Economic Principles and Applications to Natural Gas Pipelines and Other Industries, Boston: Kluwer Academic Press.

Kunreuther, Howard C., et al. (1978), Disaster Insurance Protection: Public Policy Lessons, New York: Wiley.

Laffont, Jean-Jacques and Tirole, Jean (1993), A Theory of Incentives in Procurement and Regulation, Cambridge, MA: MIT Press.

Levmore, Saul (1993), “The Case for Retroactive Taxation,” Journal of Legal Studies 22, 265 307.

Levmore, Saul (1999), "Changes, Anticipations, and Reparations," Columbia Law Review 99, 1657-1700.

Logue, Kyle D. (1996), “Tax Treatments, Opportunistic Retroactivity, and the Benefits of Government Precommitment," Michigan Law Review 94, 1129-1196.

McKenzie, Richard B. (1986), "Tax/Compensation Schemes: Misleading Advice in a RentSeeking Society," Public Choice 48, 189-194.

Merrill, Thomas W. (1986), "Rent Seeking and the Compensation Principle," Northwestern University Law Review 80, 1561-1590.

Miceli, Thomas J. and Segerson, Kathleen (1996), Compensation for Regulatory Takings: An Economic Analysis with Applications, Greenwich, CT: JAI Press.

Michelman, Frank I. (1967), "Property, Utility, and Fairness: Comments on the Ethical Foundations of 'Just Compensation' Law," Harvard Law Review 80, 1165-1258.

Mueller, Dennis C. (1989), Public Choice II, Cambridge: Cambridge University Press.

Mueller, Dennis C., ed. (1997), Perspectives on Public Choice: A Handbook, Cambridge: Cambridge University Press.

Musgrave, Richard A. (1990), "Horizontal Equity, Once More," National Tax Journal 43, 113122.

Niskanen, William A. (1971), Bureaucracy and Representative Government, Chicago: Aldine, Atherton.

Ng, Yew-Kwang (2000), "The Optimal Size of Public Spending and the Distortionary Cost of 
Taxation," National Tax Journal 53, 253-272.

Olson, Mancur (1965), The Logic of Collective Action; Public Goods and the Theory of Groups, Cambridge, MA: Harvard University Press.

Ordeshook, Peter C. (1986), Game Theory and Political Theory: An Introduction, Cambridge: Cambridge University Press.

Quinn, John and Trebilcock, Michael J. (1982), "Compensation, Transition Costs, and Regulatory Change," University of Toronto Law Journal 32, 117-175.

Ramseyer, J. Mark and Nakazato, Minoru (1989), “Tax Transitions and the Protection Racket: A Reply to Professors Graetz and Kaplow," Virginia Law Review 75, 1155-1175.

Rogerson, William P. (1984), Efficient Reliance and Damage Measures for Breach of Contract," Rand Journal of Economics 15: 39-53.

Samuels, Warren J. (1974), "Commentary: An Economic Perspective on the Compensation Problem," Wayne Law Review 21, 113-134.

Sarkar, Shounak and Zodrow, George R. (1993), "Transitional Issues in Moving to a Direct Consumption Tax," National Tax Journal 46, 359-376.

Shavell, Steven (1980), "Damage Measures for Breach of Contract," Bell Journal of Economics $11,466-490$.

Shavell, Steven (1987), Economic Analysis of Accident Law, Cambridge, MA: Harvard University Press.

Shaviro, Daniel (2000), When Rules Change: An Economic and Political Analysis of Transition Relief and Retroactivity, Chicago: University of Chicago Press.

Slemrod, Joel and Yitzhaki, Shlomo (2001), "Integrating Expenditure and Tax Decisions: The Marginal Cost of Funds and the Marginal Benefit of Projects," National Tax Journal 54, 189201.

Stark, Kirk J. (1996), “The Elusive Transition to a Tax Transition Policy,” American Journal of Tax Policy 13, 145-187.

Tullock, Gordon (1978), "Achieving Deregulation - A Public Choice Perspective," Regulation 2, 50-54.

U.S. Treasury Department (1992), Report on Integration of the Individual and Corporate Tax Systems: Taxing Business Income Once, Washington, D.C.: U.S. Government Printing Office. Usher, Dan (1995), "Victimization, Rent-Seeking and Just Compensation," Public Choice 83, 120.

Westen, Peter (1982), “The Empty Idea of Equality,” Harvard Law Review 95, 537-596.

Wickelgren, Abraham L. (2001), "Damages for Breach of Contract: Should the Government Get Special Treatment?," Journal of Law, Economics, \& Organization 17, 121-148.

Zodrow, George R. (1981), "Implementing Tax Reform," National Tax Journal 34, 401-418.

Zodrow, George R. (1985), "Optimal Tax Reform in the Presence of Adjustment Costs," Journal of Public Economics 27, 211-230. 